\title{
Inhibition Mediated by Glycinergic and GABAergic Receptors on Excitatory Neurons in Mouse Superficial Dorsal Horn Is Location-Specific but Modified by Inflammation
}

\author{
DTomonori Takazawa, ${ }^{1}$ Papiya Choudhury, ${ }^{2}$ CChi-Kun Tong, ${ }^{3}$ Charles M. Conway, ${ }^{5}$ Grégory Scherrer $, 6,7,8,9$ \\ Pamela D. Flood, ${ }^{6}$ ' Jun Mukai, ${ }^{2}$ and Amy B. MacDermott ${ }^{2,4}$ \\ ${ }^{1}$ Department of Anesthesiology, Gunma University, Maebashi, Gunma, Japan 371-8511, 2Department of Physiology and Cellular Biophysics, ${ }^{3}$ Department of \\ Dermatology, and ${ }^{4}$ Department of Neuroscience, Columbia University, New York, New York 10032, ${ }^{5}$ Neuroscience Biology, Bristol-Myers Squibb, \\ Wallingford, Connecticut 06492, ${ }^{6}$ Department of Anesthesiology, Perioperative and Pain Medicine, ${ }^{7}$ Department of Neurosurgery, ${ }^{8}$ Department of \\ Molecular and Cellular Physiology, and ${ }^{9}$ Stanford Neurosciences Institute, Stanford University School of Medicine, Palo Alto, California 94304
}

The superficial dorsal horn is the synaptic termination site for many peripheral sensory fibers of the somatosensory system. A wide range of sensory modalities are represented by these fibers, including pain, itch, and temperature. Because the involvement of local inhibition in the dorsal horn, specifically that mediated by the inhibitory amino acids GABA and glycine, is so important in signal processing, we investigated regional inhibitory control of excitatory interneurons under control conditions and peripheral inflammation-induced mechanical allodynia. We found that excitatory interneurons and projection neurons in lamina I and IIo are dominantly inhibited by GABA while those in lamina IIi and III are dominantly inhibited by glycine. This was true of identified neuronal subpopulations: neurokinin 1 receptor-expressing $(\mathrm{NK} 1 \mathrm{R}+)$ neurons in lamina I were GABA-dominant while protein kinase $\mathrm{C}$ gamma-expressing $(\mathrm{PKC} \gamma+)$ neurons at the lamina IIi-III border were glycine-dominant. We found this pattern of synaptic inhibition to be consistent with the distribution of GABAergic and glycinergic neurons identified by immunohistochemistry. Following complete Freund's adjuvant injection into mouse hindpaw, the frequency of spontaneous excitatory synaptic activity increased and inhibitory synaptic activity decreased. Surprisingly, these changes were accompanied by an increase in GABA dominance in lamina IIi. Because this shift in inhibitory dominance was not accompanied by a change in the number of inhibitory synapses or the overall postsynaptic expression of glycine receptor $\alpha 1$ subunits, we propose that the dominance shift is due to glycine receptor modulation and the depressed function of glycine receptors is partially compensated by GABAergic inhibition.

Key words: dorsal horn; GABA; glycine; inflammatory pain; synaptic inhibition

Significance Statement

Pain associated with inflammation is a sensation we would all like to minimize. Persistent inflammation leads to cellular and molecular changes in the spinal cord dorsal horn, including diminished inhibition, which may be responsible for enhance excitability. Investigating inhibition in the dorsal horn following peripheral inflammation is essential for development of improved ways to control the associated pain. In this study, we have elucidated regional differences in inhibition of excitatory interneurons in mouse dorsal horn. We have also discovered that the dominating inhibitory neurotransmission within specific regions of dorsal horn switches following peripheral inflammation and the accompanying hypersensitivity to thermal and mechanical stimuli. Our novel findings contribute to a more complete understanding of inflammatory pain.

\section{Introduction}

Laminae I and II in the spinal cord dorsal horn receive input from peripheral sensory fibers that convey information about noxious mechanical, temperature, and chemical stimuli; warm and cold temperatures; low-threshold mechanical stimuli; and itch. The dorsal horn circuitry that allows these widely varied sensory mo- 
dalities to be perceived as distinct is not visually apparent when simply observing the tightly packed neurons within this region in an acutely prepared spinal cord slice. More than $90 \%$ of the neurons in lamina I and II are relatively local interneurons with $\sim 30 \%$ of these being inhibitory and the rest being excitatory interneurons (Todd and Sullivan, 1990; Todd and Spike, 1993). Inhibition in the dorsal horn influences, at a minimum, whether mildly noxious stimuli are perceived as extremely painful (hyperalgesia) or whether simple touch is perceived as painful (allodynia; Zeilhofer et al., 2012). It is likely that inhibition in the superficial dorsal horn will be shown to help control the separation of all these sensory modalities (Ross, 2011).

Fast synaptic inhibition in the dorsal horn of the spinal cord is mediated by two amino acid neurotransmitters, GABA and glycine. When these two transmitters are coreleased, the postsynaptic receptors expressed below each release site determine which amino acid is dominant in controlling inhibition at that synapse (Jonas et al., 1998). Careful analysis of individual miniature IPSCs (mIPSCs) has been used to establish whether a neuron receives glycinergic input, GABAergic input, or both (Jonas et al., 1998; Chéry and de Koninck, 1999; Keller et al., 2001; Baccei and Fitzgerald, 2004; Mitchell et al., 2007; Rajalu et al., 2009). The contribution of GABA-mediated and glycine-mediated components are often identified using decay kinetics of the mIPSCs (Jonas et al., 1998; Chéry and de Koninck, 1999). We have taken a different approach to categorizing inhibition by setting criteria for whether the overall inhibitory inputs a neuron receives are GABA-dominant (GABA-d) or glycine-dominant (Gly-d) without establishing the details of individual release sites (Takazawa and MacDermott, 2010b). Using this approach, we previously showed that inhibitory neurons in laminae I and IIo mainly receive GABA-d input while inhibitory neurons in laminae IIi and III mainly receive Gly-d input (Takazawa and MacDermott, 2010b).

Here we elucidate the rules of inhibition in the superficial dorsal horn that allow tight control of excitation in a laminaspecific manner. Because inhibition in the dorsal horn is diminished following peripheral inflammation (Zeilhofer et al., 2012), we have also investigated the changes in inhibitory control of excitatory neurons that accompany peripheral inflammation.

\section{Materials and Methods}

Animals. All procedures used were approved by the Columbia University Institutional Animal Care and Use Committee. The mice used were homozygous for enhanced green florescent protein (EGFP) transgene with expression controlled by the mouse gad 1 gene promoter (Oliva et al., 2000). The mice, referred to as GFP-expressing inhibitory neuron (GIN) mice, were obtained from The Jackson Laboratory and interbred at our facility.

Spinal cord slice preparation. Postnatal male mice [postnatal day (P) 16-P32] were anesthetized with isoflurane and decapitated. Than the lumbar (L3-L5) region of the spinal cord was removed. Spinal cord slices were prepared as described by Takazawa and MacDermott (2010b). Briefly, spinal cords were cut into transverse slices $(400 \mu \mathrm{m})$ with a microtome (Leica VT1200S). After recovery, slices were transferred to an upright microscope (BX51WI, Olympus) equipped with fluorescence for identification of positive neurons and infrared differential interference contrast (IR-DIC) for electrophysiological recordings. Slices were continuously perfused with oxygenated Krebs' solution at a low flow rate of $2 \mathrm{ml} / \mathrm{min}$. Recordings were made at $32 \pm 1^{\circ} \mathrm{C}$. Krebs' recording solution saturated with $95 \% \mathrm{O}_{2} / 5 \% \mathrm{CO}_{2}$ had the following composition (in $\mathrm{mm}$ ):

Correspondence should be addressed to Tomonori Takazawa, Department of Anesthesiology, Gunma University, 3-39-22 Showa-machi Maebashi, Gunma, Japan 371-8511. E-mail: takazawt@gunma-u.ac.jp.

DOI:10.1523/JNEUROSCI.2354-16.2017

Copyright $\odot 2017$ the authors $\quad 0270-6474 / 17 / 372337-13 \$ 15.00 / 0$
$125 \mathrm{NaCl}, 2.5 \mathrm{KCl}, 1.25 \mathrm{NaH}_{2} \mathrm{PO}_{4}, 26 \mathrm{NaHCO}_{3}, 25$ glucose, $1 \mathrm{MgCl}_{2}, 2$ $\mathrm{CaCl}_{2}, \mathrm{pH} 7.4$.

Patch-clamp recording. Whole-cell patch recordings were made from putative excitatory EGFP-negative $\left(\mathrm{EGFP}^{-}\right)$neurons. Recording electrodes $(3-5 \mathrm{M} \Omega)$ were pulled from borosilicate glass capillaries $(0.86 \mathrm{~mm}$ inner diameter, $1.5 \mathrm{~mm}$ outer diameter) using a P97 electrode puller (Sutter Instrument). Intracellular solution included the following (in mM): 120 Cs-methanesulfonate, $10 \mathrm{Na}$-methanesulfonate, $10 \mathrm{EGTA}, 1 \mathrm{CaCl}_{2}, 10$ HEPES, 5 lidocaine N-ethyl bromide quaternary salt $\mathrm{Cl}, 0.5 \mathrm{NaGTP}, 5$ MgATP, $0.1 \%$ biocytin, $\mathrm{pH}$ adjusted to 7.2 with $\mathrm{CsOH} ; 280 \mathrm{mOsm} / \mathrm{l}$. Recordings were made from $188 \mathrm{EGFP}^{-}$neurons located in lamina I-III under voltage-clamp control at $32^{\circ} \mathrm{C}$. Among the 188 neurons, 116 were judged to be adequate for further analysis based on the following criteria: input resistance, $>350 \mathrm{M} \Omega$; access resistance, $<40 \mathrm{M} \Omega$; stable recording for $>25 \mathrm{~min}$.

Data were recorded and acquired using an Axopatch 200B amplifier and pClamp 9 software (Molecular Devices). Data were filtered at $2 \mathrm{kHz}$ and digitized at 10 or $20 \mathrm{kHz}$. After the recording was completed, images of the recorded neurons were taken using a CCD camera to document the laminar location of the neuron studied. Under IR-DIC optics, lamina II appears translucent. If the cell body of the neuron was within this translucent area, it was judged to be in lamina II. Neurons located in lamina II were further divided into IIi and IIo based on the images. If a neuron was dorsal to the translucent band, it was considered to be in lamina I. If a neuron was ventral to the translucent band, it was considered to be in lamina III. The distance between the center of soma and the border of the white and gray matter for most recorded neurons was also measured to make sure there was a clear distinction among the sample of cells belonging to different lamina (Chéry and de Koninck, 1999). The average distance for neurons obtained from mice during their third postnatal week (3W) located in lamina I, IIo, IIi, and III was $18 \pm 4 \mu \mathrm{m}(n=8), 51 \pm 4$ $\mu \mathrm{m}(n=12), 96 \pm 5 \mu \mathrm{m}(n=20)$, and $135 \pm 10 \mu \mathrm{m}(n=10)$, respectively. The distances for neurons obtained from mice during their fifth postnatal week (5W) in lamina I, IIo, IIi, and III was $21 \pm 4 \mu \mathrm{m}$ $(n=5), 49 \pm 6 \mu \mathrm{m}(n=9), 101 \pm 7 \mu \mathrm{m}(n=19)$, and $154 \pm 14 \mu \mathrm{m}(n=$ $4)$, respectively.

Recording from preidentified NK1R+ lamina I neurons. The labeling of $\mathrm{NK} 1 \mathrm{R}+$ dorsal horn neurons with fluorescent dye has been described previously (Labrakakis and MacDermott, 2003; Torsney and MacDermott, 2006; Tong and MacDermott, 2014). In brief, spinal cord slices were incubated in high- $\mathrm{Mg}^{2+}$ Krebs' solution containing 20-40 nM tetramethylrhodamine-conjugated substance $\mathrm{P}$ (TMR-substance $\mathrm{P}$ ) for $20-30 \mathrm{~min}$ at room temperature following $1 \mathrm{~h}$ of recovery at $36^{\circ} \mathrm{C}$. After unbound substance $\mathrm{P}$ was washed away for $\geq 20 \mathrm{~min}$ in an incubation chamber containing oxygenated high- $\mathrm{Mg}^{2+}$ Krebs' solution, slices were transferred to the recording chamber. NK1R + neurons were identified as expressing NK1R by clear, strong labeling with TMR-substance P. For this identification, captured frames were integrated using Scion Image. The number of frames for integration was usually $\sim 10$ but it depended upon the cell. A cell was considered positive for NK1R if the edge of its soma was rimmed with NK1R immunoreactivity. Many of these cells also had visible processes with NK1R immunoreactivity.

Electrophysiological data analysis. Spontaneous IPSCs (sIPSCs) were recorded in normal Krebs' recording solution and mIPSCs were recorded with added tetrodotoxin (TTX; $0.5 \mu \mathrm{M}$ ). Both were detected and analyzed using Mini Analysis software (Synaptosoft) off-line. The threshold for detection of sIPSCs and mIPSCs was set at three times the root mean square of the background noise, and each event was further confirmed by visual inspection after detection. When analyzing the mIPSCs, two criteria, the decay taus of mIPSCs and the effect of bicuculline on mIPSC frequency, were used to divide putative excitatory, $\mathrm{EGFP}^{-}$neurons into two distinct populations, which is similar to what was done in our previous study (Takazawa and MacDermott, 2010b). The percentage block of mIPSC frequency by bicuculline was determined as the number of mIPSCs within the last $2 \mathrm{~min}$ in the presence of TTX and bicuculline divided by the number of mIPSCs within a 2 min window just before bicuculline application in TTX.

CFA and behavior. Mice used in this study were P25-P32. Using a $50 \mathrm{ml}$ Hamilton microsyringe with a 30 gauge needle, $30 \mu \mathrm{l}$ of CFA or 
Table 1. Antibodies used in study

\begin{tabular}{|c|c|c|c|c|c|c|}
\hline $\begin{array}{l}\text { Primary } \\
\text { Antibody }\end{array}$ & Species & Dilution & Source, catalogue number & $\begin{array}{l}\text { Secondary } \\
\text { Antibody }\end{array}$ & Dilution & Source, catalogue number \\
\hline GFP & Sheep & $1: 500$ & Biogenesis, 4743 & Donkey anti-sheep lgG Alexa Fluor 488 & $1: 1000$ & Invitrogen, A-11015 \\
\hline NeuN & Mouse & $1: 1000$ & Chemicon, MAB377 & Donkey anti-mouse lgG Cy5 & $1: 1000$ & Jackson Immunoresearch, 715-175-150 \\
\hline GABA & Rabbit & 1:5000 & Sigma-Aldrich, A2052 & Donkey anti-rabbit lgG Cy3 & 1:1000 & Jackson Immunoresearch, 711-165-152 \\
\hline Glycine & Rabbit & $1: 5000$ & David Pow & Donkey anti-rabbit lgG Cy3 & $1: 1000$ & Jackson Immunoresearch, 711-165-152 \\
\hline PKC $\gamma$ & Guinea pig & 1:15000 & Strategic Biosolutions & Donkey anti-guinea pig lgG Cy5 & $1: 1000$ & Jackson Immunoresearch, 706-175-148 \\
\hline PKC $\gamma$ & Rabbit & $1: 1000$ & Santa Cruz, SC-2 & Goat anti-rabbit lgG Cy5 & 1:500 & Jackson Immunoresearch, 111-175-144 \\
\hline IB4 & Biotinylated & $1: 1000$ & Invitrogen, 121414 & Streptavidin Alexa Fluor 488 & $1: 1000$ & Invitrogen, S11223 \\
\hline NK1 & Rabbit & $1: 500$ & Novas Biologicals, NB300-101 & Goat anti-rabbit lgG Cy5 & 1:500 & Jackson Immunoresearch, 111-175-144 \\
\hline VGAT & Guinea pig & $1: 5000$ & Synaptic Systems, 131004 & Donkey anti-guinea pig lgG Cy5 & $1: 1000$ & Jackson Immunoresearch, 706-175-148 \\
\hline GLR $\alpha 1$ & Rabbit & $1: 100$ & Chemicon, AB15012 & Donkey anti-rabbit $\lg G$ Cy3 & $1: 1000$ & Jackson Immunoresearch, 711-165-152 \\
\hline Gephyrin & Mouse & $1: 1000$ & Synaptic Systems, 147021 & Donkey anti-mouse Alexa Fluor 488 & $1: 1000$ & Jackson Immunoresearch, 715-545-150 \\
\hline
\end{tabular}

saline was injected into the plantar surface of the left hindpaw. Behavioral assessments of thermal and mechanical hypersensitivity were made at 1 , 2,7 , and $14 \mathrm{~d}$ after injection.

For testing heat sensitivity, hindpaw withdrawal latency was measured in five unrestrained mice housed individually in plastic chambers (IITC Life Science) as previously described (Udesky et al., 2005; Tibbs et al., 2013). After acclimation, thermal stimulation from a movable infrared heat source was applied through an aperture under the glass plate to the hindpaw of the resting mouse. Withdrawal latency was measured as the time from the onset of the light (heat) to the time of hindlimb movement. This was repeated five times on each paw with a 1 min interval between heat applications. Methods were the same as those described previously (Tibbs et al., 2013).

For testing mechanical sensitivity, the mice were placed on an elevated mesh floor and enclosed in the same covered plastic chambers mentioned above. Von Frey filaments were pushed up through the mesh flooring and against each mouse's hindpaw. A response to a filament was identified as the withdrawal of the paw when pressure was applied for $1 \mathrm{~s}$. The von Frey filaments were applied in order of increasing pressure until a paw withdrawal took place. Ipsilateral and contralateral paws were sequentially tested with a single fiber, with fiber strengths of $0.05,0.4,0.6$, $1.1,2.5,3.3$, and $4 \times g$ tested from weakest to strongest. Then the value of the filament's bending force and that of the previous filament were averaged to identify the final value of bending force that could be tolerated by that individual mouse. Methods were the same as those described previously (Tibbs et al., 2013).

Immunohistochemistry. Lumbar spinal cord segments (L3-L6) were obtained from P30 GIN mice anesthetized with ketamine/xylazene (ketamine: $100 \mathrm{mg} / \mathrm{kg}$; xylazine: $10 \mathrm{mg} / \mathrm{kg}$, i.p.), then perfused with cold $4 \%$ formaldehyde in $0.1 \mathrm{M}$ phosphate buffer ( $\mathrm{PB})$. Tissue was postfixed for $4 \mathrm{~h}$ then cryoprotected in $30 \%$ sucrose in $0.1 \mathrm{M} \mathrm{PB}$ before cryostat sectioning.

$N e u N-E G F P-G A B A$. For experiments designed to assess the percentage of EGFP ${ }^{-}$neurons that were GABAergic, transverse sections (40 $\mu \mathrm{m})$ were collected and blocked $(1 \mathrm{~h})$ in $5 \%$ normal donkey serum (NDS) in PBS with $0.3 \%$ Triton X-100. Antibody diluents contained $1 \%$ NDS in PBS with $0.3 \%$ Triton X-100 (NDST). Triple immunostaining was performed with sheep antiserum to GFP, mouse antiserum to neuronal nuclei (NeuN), and rabbit antiserum to GABA with an overnight incubation. Secondary antibodies, applied for $3 \mathrm{~h}$, were Alexa 488conjugated anti-sheep IgG, Cy-5-conjugated anti-mouse IgG, and Cy-3conjugated anti-rabbit IgG. Colocalization of NeuN with EGFP and/or GABA was assessed using a Nikon Eclipse TE2000E microscope (40X magnification) connected to EZ-C1 image acquisition system (Nikon). For quantitative analysis, single sides of the dorsal horn from 7-8 sections per animal were used for cell counting. All cells within $150 \mu \mathrm{m}$ of the dorsal edge of the gray matter were considered to be within laminae I-III. Counts were averaged for each marker for each individual animal. Three separate averages ( $n=3$ animals) were expressed as the mean \pm SEM to give final values.

GABA or glycine-IB4-PKC $\gamma$. We performed triple immunofluorescence labeling to study the distribution GABAergic and glycinergic neu- rons in laminae I-III. We used rabbit antiserum to GABA, glycine, antiguinea pig PKC $\gamma$, and biotinylated isolectin B4 (IB4). Secondary labeling was performed with Cy-3-conjugated anti-rabbit IgG, Cy-5-conjugated anti-guinea pig IgG, and streptavidin-Alexa 488. IB4 and PKC $\gamma$ were used as regional markers of the dorsal horn. Laminae I-III were divided into six different divisions: A, lamina I (dorsal to the IB4 band); B, lamina IIo (dorsal half of IB4 band); C, dorsal part of lamina IIi (ventral part of IB4 band); D, ventral part of lamina IIi (dorsal half of PKC $\gamma$ band); E, laminae IIi-III border (ventral half of PKC $\gamma$ band); and F, lamina III (from ventral edge of PKC $\gamma$ to $150 \mu \mathrm{m}$ ventral to the outer edge of lamina I). Sections were imaged using a Nikon Eclipse TE2000E microscope ( $40 \times$ magnification) connected to an EZ-C1 confocal image acquisition system (Nikon). For quantitative analysis, one side from each dorsal horn, from seven to eight sections per animal, were used for cell counting. All cells $<150 \mu \mathrm{m}$ from the dorsal edge of the gray matter were considered laminae I-III. GABA or glycine-positive counts were averaged for each division (A-F) within each histological section from each animal. Three separate averages ( $n=3$ animals) were expressed as the mean \pm SEM to give final values.

Biocytin-NK1R or PKC $\gamma$. To assess colabeling of biocytin-filled neurons used in electrophysiology experiments, slices used for electrophysiology were fixed in $4 \%$ paraformaldehyde in $0.1 \mathrm{M} \mathrm{PB}$ overnight at $4^{\circ} \mathrm{C}$ after the recording. Slices were immersed in blocking solution $[0.1 \%$ Triton X-100, 10\% normal goat serum (NGS) in PBS] for $1 \mathrm{~h}$ at room temperature; and then incubated with rabbit antiserum to $\mathrm{PKC} \gamma$ or NK1R overnight at room temperature. Slices were rinsed in PBS, and incubated in secondary antibody diluents (1\% BSA, $0.1 \%$ Triton X-100, and $10 \%$ NGS in PBS) for $1 \mathrm{~h}$ at room temperature before incubation with streptavidin-Alexa 568 (1:500; Zymed/Invitrogen) and Cy5-goat anti-rabbit IgG for $3 \mathrm{~h}$ at room temperature. Fluorescent images were captured with a confocal microscope (Nikon). Further analysis of $z$-stacks was performed using Nikon EZ-C1 viewer software and Adobe Photoshop (Adobe Systems).

Glycine R $\alpha 1$-vesicular GABA transporter-gephyrin. To count glycinergic inhibitory synapses expressing glycine receptor $\alpha 1$ (GLR $\alpha 1)$, spinal cord sections were stained with guinea pig antiserum to vesicular GABA transporter (VGAT) as a presynaptic marker, rabbit antiserum to GLR $\alpha 1$ as a glycine receptor-specific marker, and mouse antiserum to gephyrin as a postsynaptic inhibitory synapse marker, and incubated at $4^{\circ} \mathrm{C}$ for $48 \mathrm{~h}$. Secondary antibodies were Cy5-conjugated anti-mouse IgG, Cy3-conjugated anti-rabbit IgG, and anti-guinea pig Alexa Fluor 488. Puncta were imaged using $60 \times$ magnification on a Zeiss imageacquisition system. Four images were analyzed per animal per treatment. Three animals each were used for saline and CFA treatment. Puncta were counted between 100 and $150 \mu \mathrm{m}$ (laminae IIi-III border) and 150-200 $\mu \mathrm{m}$ (laminae III/IV) ventral to the border between gray and white matter. Inhibitory synaptic puncta were scored if gephyrin and VGAT puncta overlapped by $\geq 1$ pixel. Density was calculated across each $50 \times 50 \mu \mathrm{m}$ image. While synaptic density was visibly variable within each image, overall density was averaged over each of the 12 total images analyzed at each of the two lamina locations under each of the two conditions. 
A

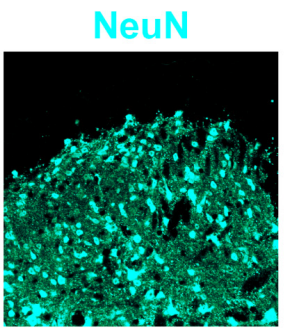

E
B

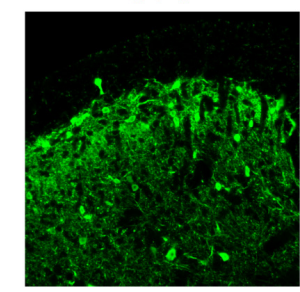

$\mathbf{F}$

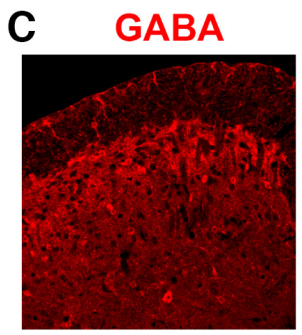

G
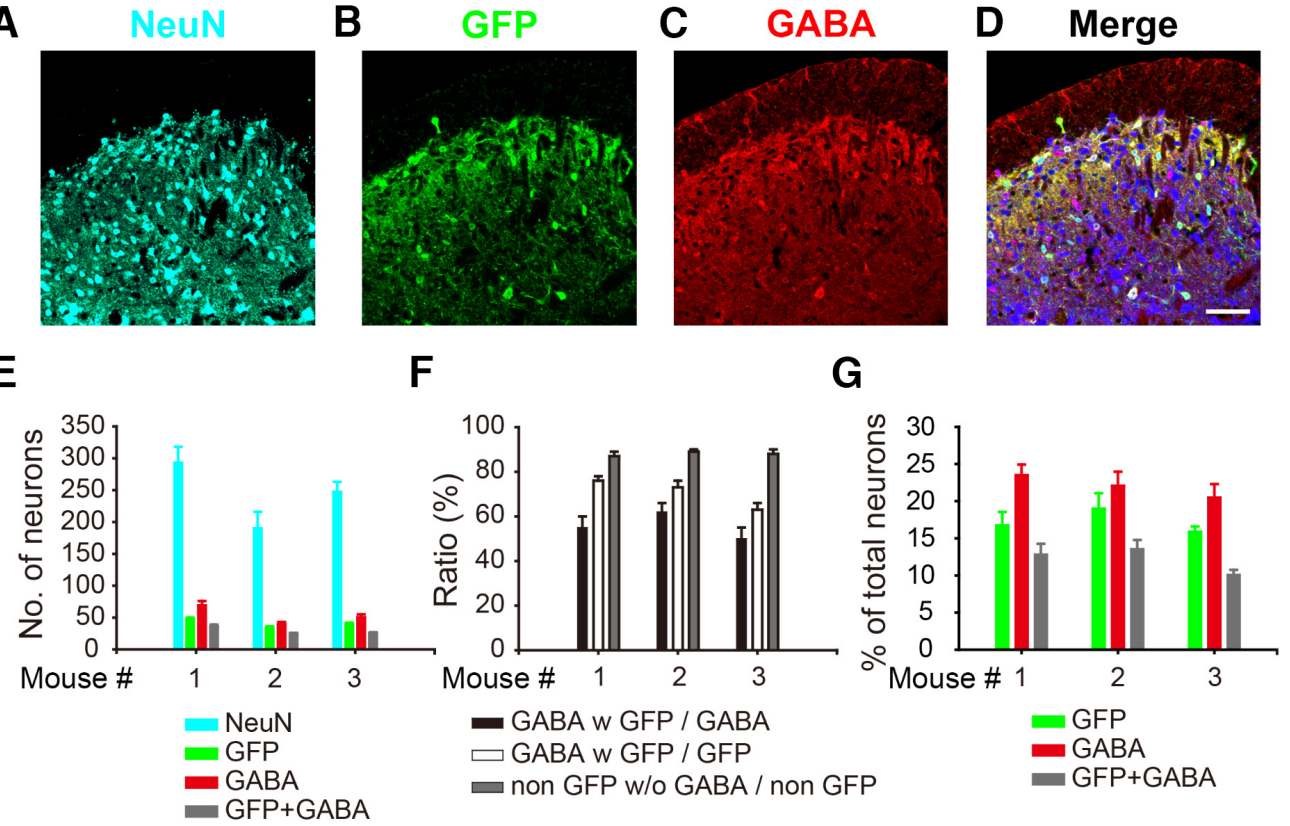

Figure 1. Identification of excitatory neurons in spinal cord slice preparations obtained from GAD67 GIN mice. $A-C$, Lamina I-III dorsal horn neurons from adult (P29) GIN mice $(n=3)$ were stained with antibodies against NeuN (A, pseudo color), EGFP (B), and GABA (C). D, Merged images of NeuN, EGFP, and GABA immunoreactivity. Scale bar, $50 \mu \mathrm{m}$. Dorsal top, medial left in each panel. $\boldsymbol{E}$, Total number of neurons expressing NeuN (cyan bars), EGFP (green bars), GABA (red bars), and EGFP with GABA (gray bars) in lamina I-III dorsal horn of adult (P29) GIN mice ( $n=3$ ). Neurons located in a single plane were counted. $\boldsymbol{F}$, The ratio for GABA with EGFP over total GABA (black bars), EGFP with GABA over total EGFP (white bars), and non-EGFP without GABA over total non-EGFP (gray bars). These results suggest that most ( $~ 90 \%)$ non-EGFP neurons are excitatory. G, The percentage of EGFP and GABA-positive neurons, and GABA with EGFP neurons, as a function of total NeuN-positive neurons. The numbers and ratios shown here are averaged values obtained from eight slices for each animal. Results are presented as means \pm SEM.

All antibodies used in this study are listed in Table 1 for easy referencing.

Statistics. Results are presented as mean \pm SEM. Statistical tests were performed using Prism software (GraphPad). Differences between groups are considered significant for $p<0.05$.

\section{Results}

Identification of putative excitatory neurons in the spinal cord slice preparations

The spinal cord dorsal horn has multiple polysynaptic excitatory pathways that drive output projection neurons and are controlled by inhibitory interneurons (Torsney and MacDermott, 2006; Miraucourt et al., 2007; Ross et al., 2010; Wang et al., 2013). We have previously shown that inhibitory interneurons in the spinal cord dorsal horn, representing $\sim 30 \%$ of the neurons there, are themselves subject to lamina-specific inhibitory control (Takazawa and MacDermott, 2010b). The neurons that are neither inhibitory nor projection neurons, which comes to $\sim 70 \%$ of the neurons in laminae I-III of the dorsal horn, are assumed to be glutamatergic interneurons (Todd, 2010). In this study we specifically focus on these excitatory interneurons using transgenic GIN mice, first described by Oliva et al. (2000), to allow us to identify our neurons of interest.

In previous studies, nearly all inhibitory neurons within the superficial laminae of the dorsal horn were reported to be GABAergic while glycine is coexpressed with GABA in a subpopulation of those neurons (Todd and Sullivan, 1990; Polgár et al., 2013). In GIN mice, not all GABAergic neurons express EGFP (Heinke et al., 2004; Dougherty et al., 2005, 2009). It follows that the absence of EGFP expression does not necessarily mean a neuron is excitatory. GAD67-driven EGFP expression in GABAergic neurons of this transgenic line has been shown to vary with age or location. In one study, one-third of lamina II GABAergic neurons were $\mathrm{EGFP}^{+}$in adult mice (Heinke et al., 2004), while in another study, two-thirds of lamina I GABAergic neurons were $\mathrm{EGFP}^{+}$in P14 mice (Dougherty et al., 2005). To establish this relationship in laminae I-III of $\sim$ P30 mice, we have performed triple fluorescence imaging using antibodies to the pan-neuronal marker, NeuN, to the inhibitory transmitter, GABA, and to transgenically expressed EGFP ( $n=3$ animals; Fig. $1 A-D)$. The total number of neurons in each field was defined as all cells expressing NeuN (Fig. 1E). The total number of neurons with colocalized GABA, the total number of neurons with colocalized EGFP, and the total number of neurons with both GABA and EGFP are shown in Figure $1 E$. Based on these results, we calculated the ratio of $\mathrm{EGFP}^{+}$neurons within the total population of GABAergic neurons (Fig. $1 F$, black bars; $55 \pm 5,62 \pm 4$, and $50 \pm 5 \%$ ) and the ratio of GABAergic neurons within the total population of $\mathrm{EGFP}^{+}$neurons (Fig. $1 F$, white bars; $76 \pm 2,73 \pm 3$, and $63 \pm$ $3 \%)$. Furthermore, we found that nearly $90 \%$ of neurons without EGFP are not GABAergic neurons (Fig. $1 F$, gray bars $87 \pm 2,89 \pm$ 1 , and $88 \pm 2 \%)$. Therefore, we recorded from EGFP ${ }^{-}$neurons as a way of enriching for excitatory neurons. We will call these neurons putative excitatory neurons.

\section{Two distinct populations of EGFP ${ }^{-}$neurons defined by synaptic inhibitory inputs}

Excitatory neurons in the dorsal horn are known to be heterogeneous in their neurochemistry, firing properties, and afferent inputs they receive. They thus may also be heterogeneous in how their excitability is regulated. We have previously shown that inhibitory dorsal horn neurons are inhibited in a region-specific manner. The neurons at the lamina II-III border receive synapses that are predominantly glycinergic while the neurons at laminae I and IIo receive synapses that are predominantly GABAergic (Takazawa and MacDermott, 2010b). To determine whether different subpopulations of putative excitatory neurons are regu- 
A



B
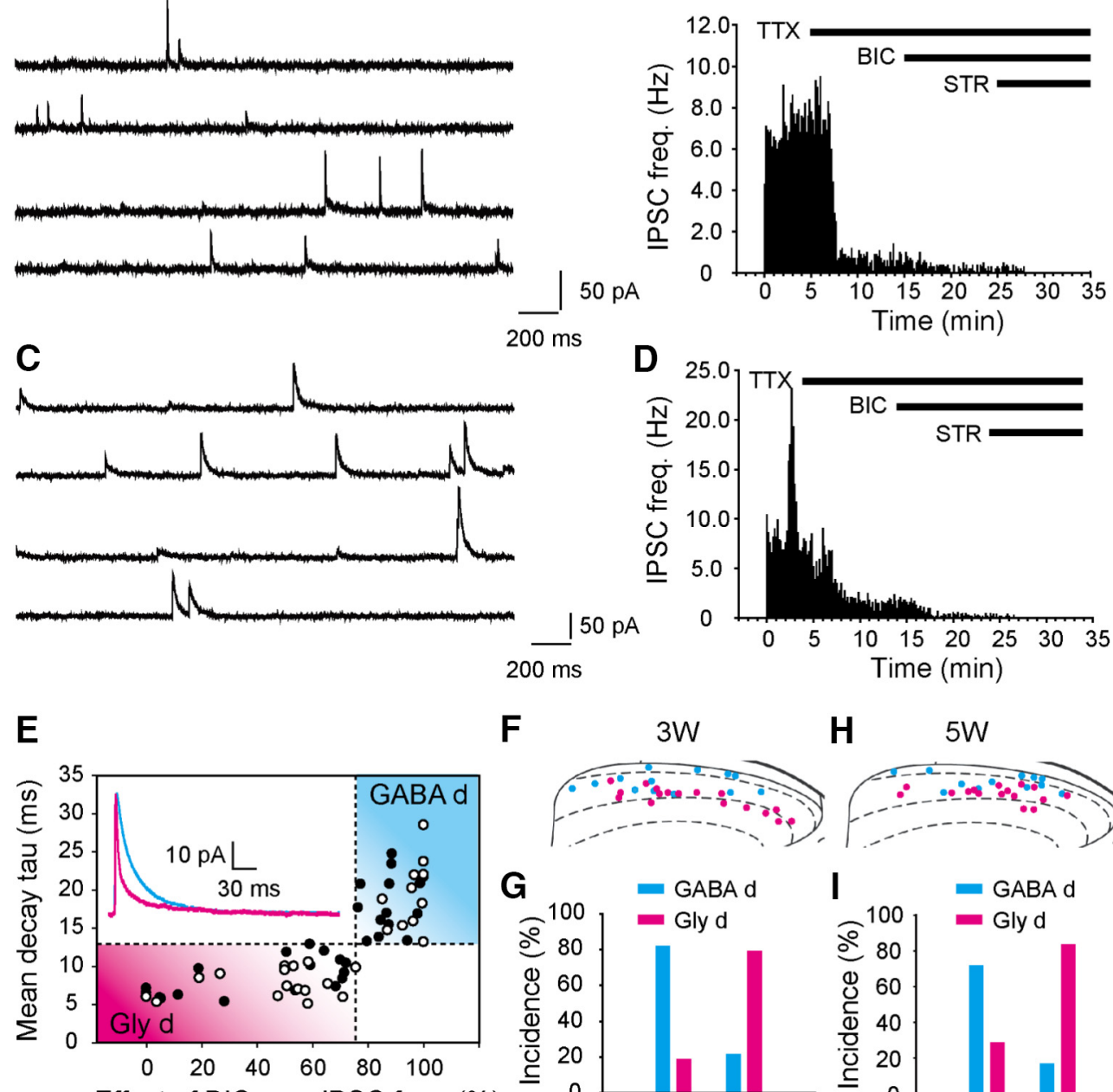

$\mathbf{F}$

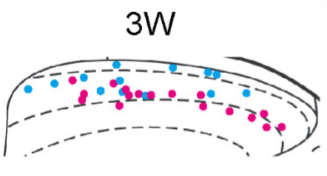

H $5 \mathrm{~W}$

Effect of BIC on mIPSC freq. (\%)
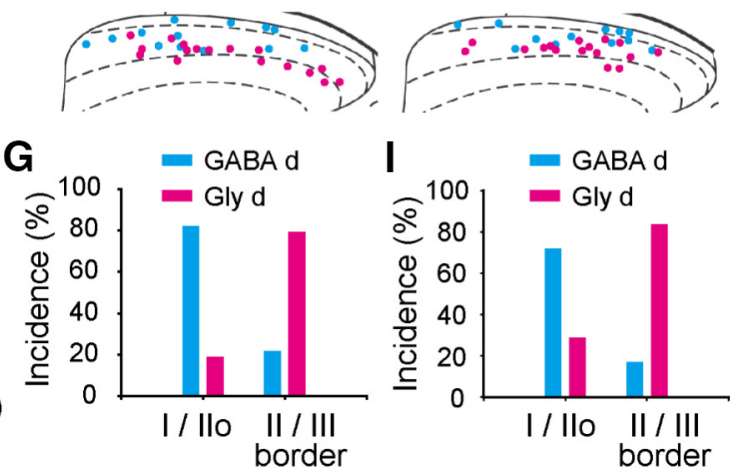

Figure 2. Excitatory neurons in the spinal cord dorsal horn have regionally distinct properties of synaptic inhibitory input. $A, C$, Representative current traces obtained from a neuron having bicuculline (BIC; $10 \mu \mathrm{M}$ )-resistant mIPSCs with relatively fast kinetics $(\boldsymbol{A})$ and from a neuron having BIC-sensitive mIPSCs with relatively slow kinetics (C). Holding membrane potential was $0 \mathrm{mV}$. $\boldsymbol{B}$, $D$, Histograms for mIPSC frequency corresponding to left traces. $E$, Excitatory neurons from mouse dorsal horns at 3 and 5 weeks ( $3 W$ and $5 W$ ) of age could be divided into two distinct populations, Gly-d and GABA-d, on the basis of the property of inhibitory synaptic inputs. Filled and open circles indicate individual neurons at $3 \mathrm{~W}$ and $5 \mathrm{~W}$, respectively. The inset shows the typical averaged trace for the mIPSC of Gly-d (pink; decay taus, $5.0 \mathrm{~ms}$, averaged from 36 events in same neuron as $\boldsymbol{A}$ and $\boldsymbol{B}$ ) and GABA-d (blue; decay taus, $20.0 \mathrm{~ms}$, averaged from 92 events in same neuron as $\boldsymbol{C}$ and $\boldsymbol{D}$ ) neurons. $\boldsymbol{F}, \boldsymbol{H}$, Soma locations of Gly-d (pink circles) and GABA-d (blue circles) neurons at P16-P18 (3W; $\boldsymbol{F})$ and at P29-P32 (5W; $\boldsymbol{H})$. Right and top of the schematic diagram shows lateral and dorsal edge of the dorsal horn, respectively. Laminae I, II, and III are separated by dotted lines. $G, I$, In both populations corresponding to $\boldsymbol{F}$ and $\boldsymbol{H}$, Gly-d neurons were the major population at the lamina II-III border ( $3 \mathrm{~W}: n=19 ; 5 \mathrm{~W}: n=12$ ), while GABA-d neurons (blue bars) were the major population in laminae l and Ilo ( $3 \mathrm{~W}: n=12 ; 5 \mathrm{~W}: n=14 ; p<0.01$ for both at $3 \mathrm{~W}$ and $5 \mathrm{~W}$, Fisher's exact test). Bars indicate incidence of neurons located in laminae I and Ilo, and at the lamina II-III border.

lated differently by inhibition in a lamina-specific manner similar to inhibitory neurons, we first analyzed mIPSCs recorded from $\mathrm{EGFP}^{-}$neurons. Mice in their third and fifth postnatal weeks ( $3 \mathrm{~W}$ and $5 \mathrm{~W} ; 3 \mathrm{~W}: n=31$; range, $\mathrm{P} 16-\mathrm{P} 18$; mean, $\mathrm{P} 16.6 \pm 0.1$; $5 \mathrm{~W}: n=28$; range, P29-P31; mean P30.2 \pm 0.1 ) were used. Neurons were voltage clamped at $0 \mathrm{mV}$ for recording mIPSCs.

mIPSC frequency was measured for each neuron tested in the presence of TTX, then with added bicuculline. Strychnine was added at the end of each experiment to confirm that all mIPSCs were GABA-mediated or glycine-mediated. Figure $2 A, B$ shows data from a neuron in which the MIPSC frequency (after TTX) was only slightly changed by bicuculline. Figure $2 C, D$ shows data from a neuron in which mIPSC frequency was strongly affected by bicuculline.

Based on inhibitory synaptic properties, including the effect of bicuculline on mIPSC frequency and on mean decay tau of
mIPSCs, putative excitatory neurons were readily divided into two distinct populations, either Gly-d or GABA-d. We did not fit the decay phase of individual mIPSCs using an exponential function while defining GABA- $d$ and Gly-d neurons because mIPSCs could theoretically exhibit up to four decay components if the underlying $\mathrm{GABA}_{\mathrm{A}}$ receptor and glycine receptor components of the mIPSCs were both double-exponential (Mitchell et al., 2007). Gly-d neurons (3W: $n=18$; 5W: $n=16$ ) had mIPSCs with relatively fast decay taus, where tau was defined as the time to decay to $33 \%$ of the peak amplitude and by low sensitivity to bicuculline (Fig. 2A,B,E, inset). In contrast, GABA-d neurons ( $3 \mathrm{~W}: n=13 ; 5 \mathrm{~W}: n=12$ ) had mIPSCs with relatively slow decay taus and high sensitivity to bicuculline (Fig. $2 C, D, E$, inset). Gly-d neurons had decay taus $<13 \mathrm{~ms}$ while GABA-d neurons were defined as having mIPSC decay taus $>13 \mathrm{~ms}$ (Fig. 2E). Neurons with $<76 \%$ decrease in frequency in bicuculline were considered 
Gly-d neurons while neurons with $>76 \%$ decrease of mIPSC frequency in bicuculline were considered GABA-d neurons (Fig. $2 E)$. The two criteria of decay tau and bicuculline sensitivity of mIPSC frequency independently separated the same two populations of neurons. These criteria are the same as those used previously for inhibitory dorsal horn neurons (Takazawa and MacDermott, 2010b).

\section{GABA-d and Gly-d putative excitatory neurons are in different regions of the superficial dorsal horn}

Identification of two populations of putative excitatory neurons based on inhibitory synaptic input raises the question of whether these neurons have distinct locations within the dorsal horn or are mixed randomly throughout laminae I-III. To investigate this question, the location of each recorded neuron categorized as Gly-d and GABA-d from 3W animals was plotted as shown in Figure $2 F$. From visual inspection, it is evident that Gly-d neurons are mainly located somewhat deeper in the superficial dorsal horn while GABA-d neurons are generally located more superficially. To quantify the distribution of Gly-d and GABA-d neurons, the percentage of each type of neuron located in laminae I and IIo (laminae I/IIo) and in lamina IIi and the dorsal border of III (lamina II-III border) is plotted in Figure 2G. It is clear that excitatory Gly-d neurons (pink bars) are the major population at the lamina II-III border $(n=19)$ while EGFP ${ }^{-}$GABA-d neurons (blue bars) are the major population in laminae I/IIo $(n=12$; $p<0.01$, Fisher's exact test).

We next determined whether region specificity of synaptic inhibitory input changed developmentally. We recorded inhibitory inputs to putative excitatory neurons obtained from animals during their fifth postnatal week (5W). Again, those neurons could be divided into two distinct populations based on synaptic inhibitory input properties using the same definition as neurons obtained from $3 \mathrm{~W}$ animals. Gly-d neurons (pink bars) were prominent at the lamina II-III border $(n=12)$ and GABA-d neurons (blue bars) were a major population in laminae I/IIo ( $n=14$; Fig. $2 H, I ; p<0.01$, Fisher's exact test), suggesting that region specificity of synaptic inhibitory input onto putative excitatory neurons was preserved after maturation was complete. In addition, regional properties for synaptic inhibitory input were the same, no matter what the type of neuron (i.e., excitatory or inhibitory).

\section{The distribution of neurons expressing glycine or GABA in the superficial dorsal horn}

Gly-d or GABA-d synaptic transmission can be due to the relative amounts of glycine or GABA released at synapses, to the composition of the receptors expressed at postsynaptic sites, or to both. Neurons inhibitory to other lamina II neurons are distributed within the same dorsoventral dimension relative to those neurons (Kato et al., 2009; Yasaka et al., 2010). Thus, the laminar distribution of inhibitory neurons expressing glycine or GABA may be similar to the distribution of Gly-d and GABA-d neurons. To investigate this possibility, we performed immunostaining for glycine and GABA. We used antibodies against IB4 and PKC $\gamma$ to standardize the empirical definition of laminae in superficial dorsal horn (see Materials and Methods). The regions stained with IB4 and PKC $\gamma$ antibody were clearly separated (Fig. $3 A, B$ ). The distribution pattern of glycine-positive (Fig. $3 A, D$ ) and GABApositive (Fig. $3 B, D$ ) neurons in laminae I-III showed that glycine-expressing neurons are more prominent at the lamina IIi-III border whereas GABA-expressing neurons are more prominent near laminae I/IIo. These results show that the loca- tion of glycinergic inhibitory neurons at the lamina II-III border is consistent with the dominance of glycinergic synaptic control of excitatory neurons in that region. The more dorsal lamina I and IIo inhibitory neurons were mainly GABAergic, which is consistent with the finding that putative excitatory neurons in that region received synapses that were predominantly GABA-d. These findings imply that the presence of both transmitter and receptor is important for determining which inhibitory amino acid transmitter is dominant in different regions of the dorsal horn.

\section{The distribution of Gly-d and GABA-d neurons was independent of recording conditions, including membrane holding potential}

We used low- $\mathrm{Cl}^{-}$-containing pipette solution combined with voltage-clamping membrane potential at $0 \mathrm{mV}$ to investigate inhibitory control of putative excitatory dorsal horn neurons in most of our experiments. However, under these strongly depolarized conditions, it is likely that $\mathrm{Ca}^{2+}$ enters the neuron through voltage-gated $\mathrm{Ca}^{2+}$ and NMDA receptors. This $\mathrm{Ca}^{2+}$ may result in modification of glycine and $\mathrm{GABA}_{\mathrm{A}}$ receptor function, influencing our assessment of neurons as Gly- $\mathrm{d}$ and GABA-d. To rule out this possibility, we used a pipette solution containing a high concentration of $\mathrm{Cl}^{-}$, shifting the $\mathrm{Cl}$ reversal potential close to $0 \mathrm{mV}$. Under these conditions, neurons could be voltage-clamped at $-70 \mathrm{mV}$ and mIPSCs seen as inward currents. Recording in the presence of antagonists for both AMPA and NMDA receptors enabled us to isolate inhibitory synaptic currents during whole-cell patch-clamp recording at $-70 \mathrm{mV}$. Nineteen neurons obtained from $3 \mathrm{~W}$ GIN mice were divided into Gly-d and GABA-d neurons (Fig. 4A-E) using the same definition as was used previously. Among 19 neurons, 11 were defined as Gly-d, while 8 were defined as GABA-d. As shown in Figure $4 F, G$, the distribution pattern of Gly-d and GABA-d neurons was similar to that of neurons recorded at $0 \mathrm{mV}$ (Fig. $2 F, G$ ), suggesting that the effect of recording membrane potential on the interpretation of whether a neuron was GABA-d and Gly-d was negligible.

\section{Inhibition of specific subtypes of excitatory neurons}

Many projection neurons in lamina I express receptors for substance P, the NK1 receptors (Cameron et al., 2015). We have previously shown that lamina I, NK1R+ neurons receive highthreshold (A $\delta / C$ fiber) monosynaptic and/or polysynaptic inputs under control conditions (Torsney and MacDermott, 2006). However, blockade of local glycinergic and GABAergic inhibition by applying antagonists to these receptors revealed significant polysynaptic A fiber input to the lamina I NK1R + neurons. This revealed input was predominantly $\mathrm{A} \beta$ fiber mediated, suggesting that polysynaptic low-threshold input onto lamina I, NK1R+ neurons may be an underlying component of the hypersensitivity present in chronic pain states (Torsney and MacDermott, 2006; Tong and MacDermott, 2014). Despite this observation, we do not know whether glycinergic or GABAergic neurons synapse directly onto NK1R+ neurons and suppress their neuronal excitability. To address this issue, whole-cell patch-clamp recordings were performed after prelabeling NK1R + neurons in spinal cord slices incubated with TMR-substance P (see Materials and Methods; Labrakakis and MacDermott, 2003; Torsney and MacDermott, 2006). Figure $5 A$ shows an example of an NK1R + neuron identified in lamina I from which a recording was made. Immunostaining of the recorded neurons, as indicated by staining for biocytin (Fig. 5B), was performed to confirm that the 


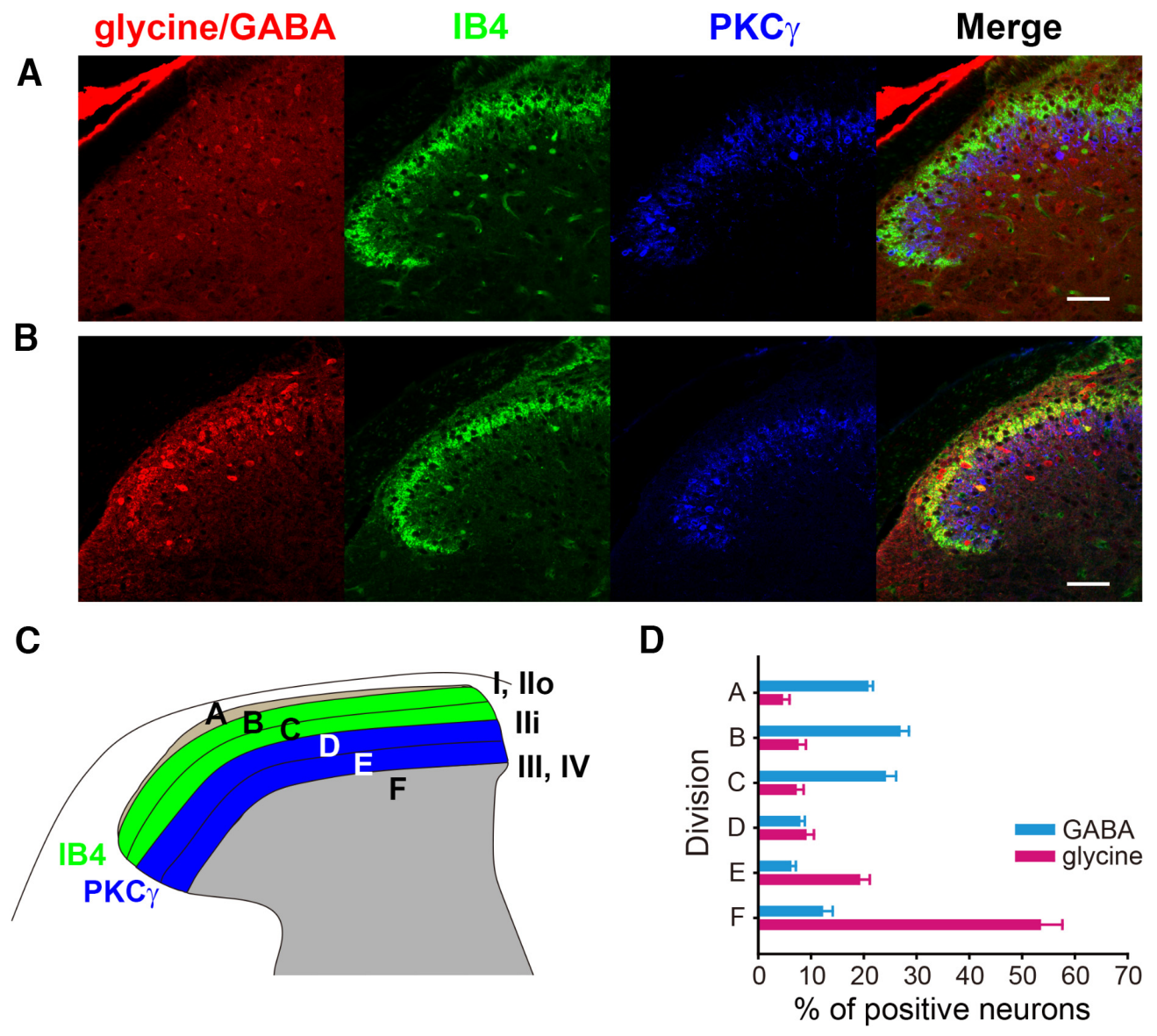

Figure 3. The distribution of neurons with glycine and GABA immunoreactivity. $A, B$, Lamina I-III dorsal horn neurons from adult (P28) GIN mice $(n=3)$ were stained with antibodies against glycine $(\boldsymbol{A})$ and GABA $(\boldsymbol{B})$. C, lllustration showing divisions for counting number of stained neurons determined by IB4 and PKC $\gamma$ immunoreactivity. $\boldsymbol{D}$, The percentage of glycine-positive (pink) and GABA-positive (blue) neurons in each division was calculated as a function of the total number of glycine-positive and GABA-positive neurons counted in all divisions, respectively. Scale bars, $50 \mu \mathrm{m}$.

prelabeled and recorded neurons were immunopositive for antibody to NK1R. Pink pixels show immunoreactivity to NK1R in the recorded neuron (Fig. 5C). We used mIPSCs to investigate the type of inhibitory synaptic input received by lamina I, $\mathrm{NK} 1 \mathrm{R}+$ neurons obtained from $3 \mathrm{~W}$ GIN mice. The neuron shown in Figure $5 A-C$ was GABA-d neurons as shown in Figure 5G. Six of seven NK1R+ neurons were GABA-d (Fig. 5I).

$\mathrm{PKC} \gamma+$ neurons receive innocuous input via $\mathrm{A} \beta$ fibers at the lamina IIi-III border (Neumann et al., 2008; Peirs et al., 2014). They are part of a local excitatory circuit that mediates dynamic mechanical allodynia after loss of glycinergic inhibitory control (Miraucourt et al., 2007; Lu et al., 2013). These studies suggested that glycinergic inhibition of PKC $\gamma+$ neurons normally closes a gate for a low-threshold pathway to lamina I. This pathway opens following injury, producing dynamic mechanical allodynia. However, evidence directly showing how $\mathrm{PKC} \gamma+$ neurons are inhibited is still lacking. To address this issue, we recorded from randomly chosen putative excitatory neurons. Following recording, spinal cord slices were immunostained using antibody against PKC $\gamma$. Twenty-seven neurons were successfully filled with biocytin and, of those, four (two lamina IIi, two lamina III) had PKC $\gamma$ immunoreactivity. Figure $5 D-F$ shows one of those neurons recognized as $\mathrm{PKC} \gamma+$. Among four $\mathrm{PKC} \gamma+$ neurons, three were defined as Gly-d neurons (Fig. 5I).

These data demonstrate that NK1R + neurons predominantly received $\mathrm{GABA}_{\mathrm{A}}$ receptor-mediated synaptic inhibitory inputs and that $\mathrm{PKC} \gamma+$ neurons predominantly received glycine receptor-mediated synaptic inhibitory inputs. This is consistent with our earlier results showing that the neurons at laminae I and IIo receive synapses that are predominantly GABAergic while the neurons at the lamina IIi-III border receive synapses that are predominantly glycinergic (Fig. 2).

\section{Change from Gly-d to GABA-d following CFA-induced paw inflammation}

Thermal and mechanical hypersensitivity develop following CFA-induced peripheral inflammation and it has been suggested that this is due to diminished glycinergic inhibition (Müller et al., 2003; Harvey et al., 2004). Because glycinergic inhibition of excitatory interneurons is dominant in lamina IIi and suppression of glycinergic inhibition in this region results in mechanical allodynia (Miraucourt et al., 2007), we hypothesized that inflammation may decrease glycinergic dominance in the lamina IIi-III border and alter the balance between excitatory and inhibitory synaptic activity. To test this, recordings were made from neurons located in the lamina IIi-III border taken from mice injected with saline or CFA 2-3 d earlier. After establishing that both thermal and mechanical hypersensitivity developed in the CFAinjected animals (Fig. 6A,B), spontaneous excitatory and inhibitory synaptic events were recorded. There was an increase in the frequency of excitatory activity and a decrease in inhibitory activity, producing an overall increase in excitation over inhibition (Fig. $6 \mathrm{C}$ ). At the same time, there was an increase in the amplitude of excitatory synaptic events with no significant change de- 
A

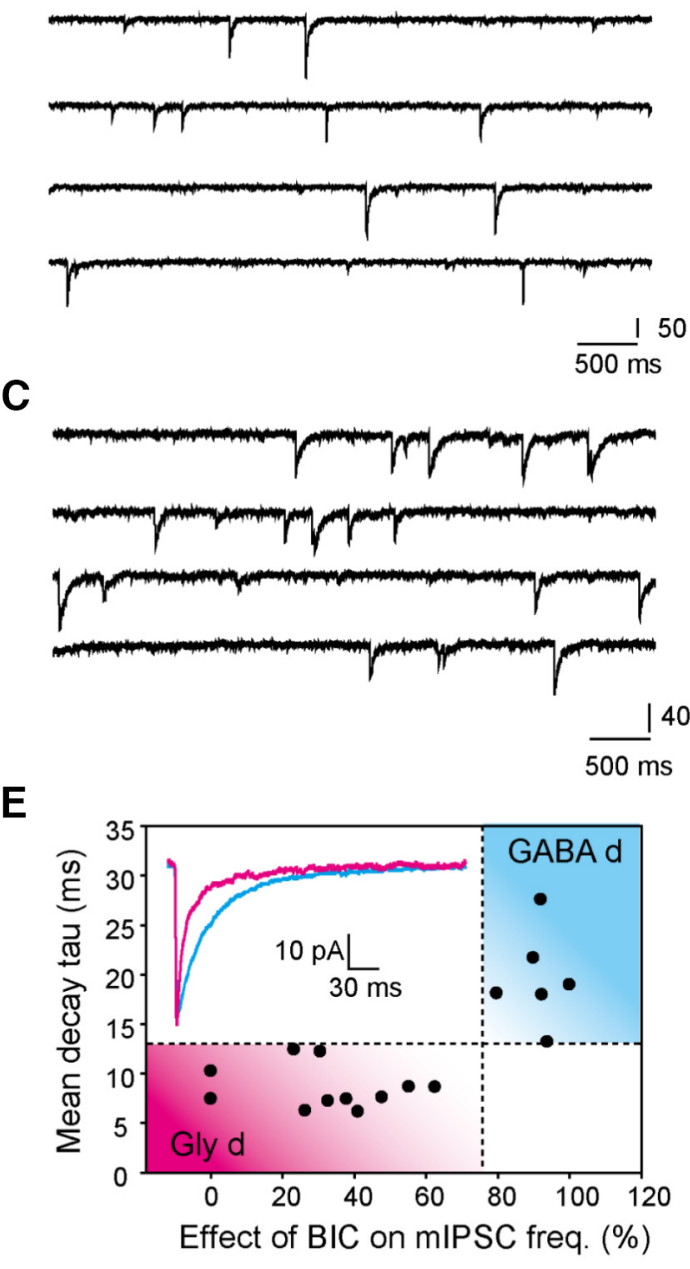

B



D

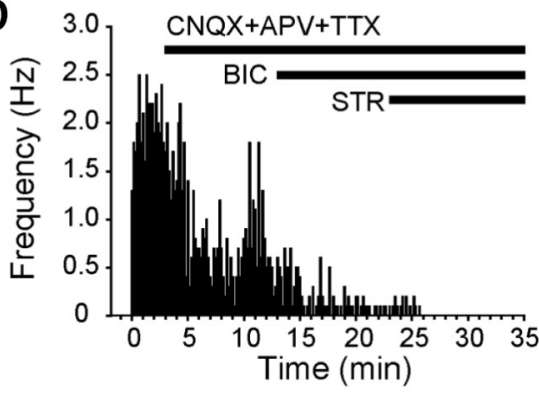

$\mathbf{F}$
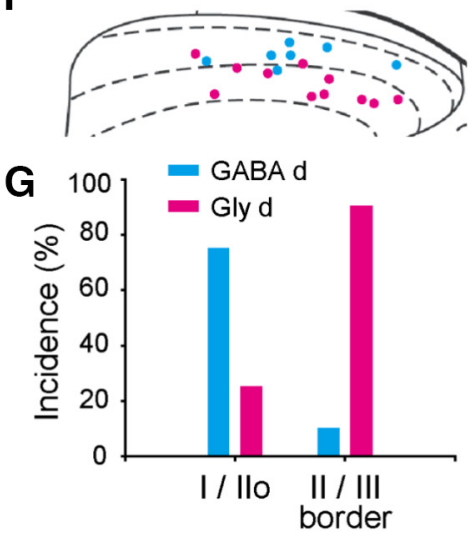

Figure 4. The distribution of Gly-d and GABA-d excitatory neurons at 3 weeks of age did not change when using high-chloride-containing internal solution. $A, C$, Representative current traces obtained from a neuron having bicuculline (BIC; $10 \mu \mathrm{m})$-resistant mIPSCs with relatively fast kinetics $(\boldsymbol{A})$, and a neuron having BIC-sensitive mIPSCS with relatively slow kinetics $(\boldsymbol{C})$. Holding membrane potential was $-70 \mathrm{mV} . \boldsymbol{B}, \boldsymbol{D}$, Histograms for mIPSCs frequency correspond to left traces. $\boldsymbol{E}$, Excitatory neurons from mouse dorsal horn could be divided into two distinct populations, Gly-d or GABA-d, on the basis of the property of inhibitory synaptic inputs. Filled circles indicate individual neurons. The inset shows the typical averaged trace for the mIPSC of Gly- $d$ (pink; decay taus, $9.4 \mathrm{~ms}$, averaged from 41 events in same neuron as $\boldsymbol{A}$ and $\boldsymbol{B}$ ) and GABA-d (blue; decay taus, $32.3 \mathrm{~ms}$, averaged from 58 events in same neuron as $\boldsymbol{C}$ and $\boldsymbol{D}$ ) neurons. $\boldsymbol{F}$, Soma locations of Gly-d (pink circles) and GABA-d (blue circles) neurons. Right and top of the schematic diagram show lateral and dorsal edge of the dorsal horn, respectively. Laminae I, II, and III are separated by dotted lines. G, Gly-d neurons were the major population at the lamina II-III border $(n=10)$, while GABA-d neurons (blue bars) were the major population in laminae I and IIo $(n=8 ; p<0.05$, Fisher's exact test). Bars indicate incidence of neurons located in laminae I and IIo, and at the lamina II-III border.

tected in the amplitude of inhibitory events (Fig. 6D). Thus, the excitatory charge transfer was increased in excitatory neurons in lamina IIi following exposure to CFA (Fig. 6E).

To determine whether there is a change in Gly-d under CFA conditions, we compared mIPSCs in lamina IIi from salineinjected and CFA-injected animals. The overall mIPSC frequency was decreased in lamina IIi of CFA-injected animals (Fig. 7A). These mIPSCs were subjected to the same analysis as described earlier to reveal whether the neurons were GABA-d and Gly-d. The analysis using bicuculline sensitivity and mean decay tau showed a similar clustering into the two types of synaptic physiology (Fig. 7B). Interestingly, however, the excitatory neurons in lamina IIi shifted to a more GABA-d phenotype following CFA injection (Fig. 7C-E).

The change from mainly Gly-d to more GABA-d following CFA could be due to an alteration in inhibitory synapse number, decreased glycine receptor expression at existing synapses, or a change in functioning of existing receptors. To address this question, we performed immunohistochemistry with antibodies to three elements in the inhibitory synapses: presynaptic VGAT (Fig. $8 A$ ), postsynaptic GABA and glycine receptor-associated scaffolding protein gephyrin (Fig. 8B), and the GLR $\alpha 1$ (Fig. 8C).

Glycine receptors are pentameric ligand-gated ion channels composed of $\alpha$ and $\beta$ subunits assembled in a 2:3 stoichiometry (i.e., $2 \alpha 3 \beta)$. Initially, the $\alpha 1 / \beta$ heteromer was considered the dominant glycine receptor isoform at adult synapses in the spinal cord. Later, the presence of $\alpha 3$ subunit containing glycine receptors in laminae I and II and their role in inflammatory pain were reported (Harvey et al., 2004; Lynch and Callister, 2006). More recently, Graham et al. explored the presence of various glycine receptor subunits in this region using spasmodic mouse, which has a naturally occurring mutation (A52S) in the $\alpha 1$ subunits of the glycine receptor (Graham et al., 2011). They found that the response to exogenously applied glycine was reduced in $>75 \%$ of 
A TMR-SP


Effect of BIC on mIPSC freq. (\%)
B biocytin



E biocytin

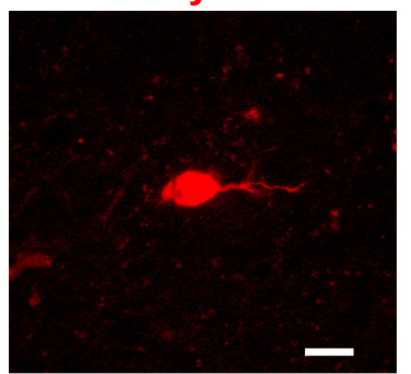

\section{C biocytin/NK1}

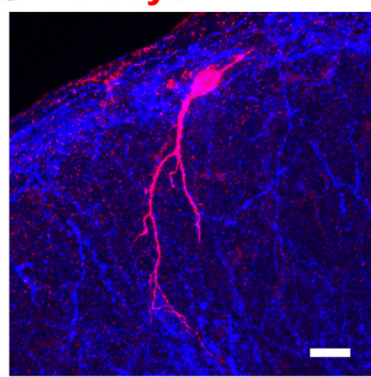

\section{F biocytin/PKC $\gamma /$ eGFP}

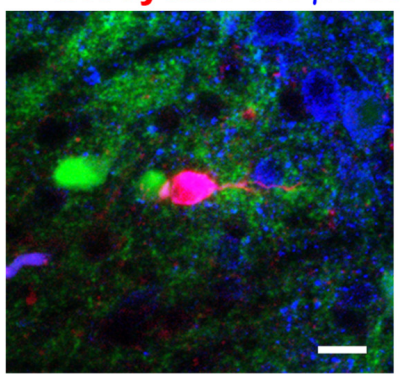

H

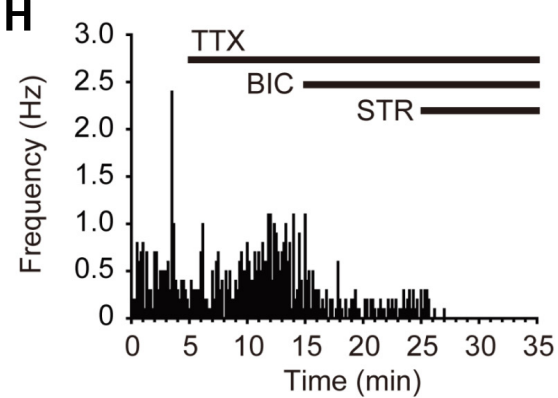

$\mathbf{J}$

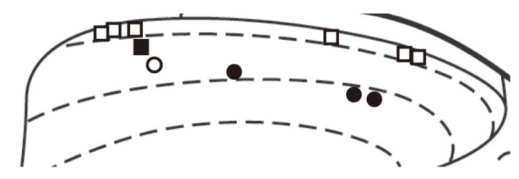

- $\mathrm{NK} 1+$, Gly d

$\square \mathrm{NK} 1+, \mathrm{GABA} d$

- PKC $\gamma$, Gly d

O PKC $\gamma$, GABA d

Figure 5. Properties of inhibitory synaptic inputs onto NK1R + and PKC $\gamma+$ neurons. $\boldsymbol{A}-\boldsymbol{C}$, Identification of an NK1R + neuron in spinal cord slice preparation. $\boldsymbol{A}$, Optical image for TMR substance-P-labeled neuron obtained before electrophysiological recording. $\boldsymbol{B}, \boldsymbol{C}$, Confocal images obtained from same neuron as $\boldsymbol{A}$ following fix and staining for biocytin-filled recorded neuron and with anti-NK1R. $\boldsymbol{D}-\boldsymbol{F}$, Confocal images for PKC $\gamma+$, biocytin-filled recorded neuron, and merged image. $\boldsymbol{G}, \boldsymbol{H}$, Histograms for mIPSC frequency corresponding to neurons shown in $\boldsymbol{A}-\boldsymbol{C}$ and $\boldsymbol{D}-\boldsymbol{F}$, respectively. I, NK1 + and PKC $\gamma+$ neurons could be divided into two distinct populations, Gly-d or GABA-d, on the basis of the property of inhibitory synaptic inputs. NK1 + and PKC $\gamma+$ neurons were indicated by squares and circles, respectively. The inset shows the typical averaged trace for the mIPSC of PKC $\gamma+$ neurons (pink; decay taus, 10.5 ms, averaged from 54 events in same neuron as $\boldsymbol{D}, \boldsymbol{E}$, and $\boldsymbol{H}$ ), and NK1R + neurons (blue; decay taus, $16.6 \mathrm{~ms}$, averaged from 74 events in same neuron as $\boldsymbol{A}-\boldsymbol{C}$ and $\boldsymbol{G}$ ). $\boldsymbol{J}$, Soma locations of NK1R $+($ squares) and PKC $\boldsymbol{\gamma}+($ circles) neurons. Right and top of the schematic diagram show lateral and dorsal edge of the dorsal horn, respectively. Laminae I, II, and III are separated by dotted lines. Scale bars: $\boldsymbol{A}, \boldsymbol{B}, \boldsymbol{D}-\boldsymbol{F}, 20 \mu \mathrm{m} ; \boldsymbol{C}, 10 \mu \mathrm{m}$.

neurons tested in the spasmodic sample, suggesting that these neurons contained either $\alpha 1-\beta$ or even $\alpha 1 / \alpha 3-\beta$ isoforms while the remaining neurons showed normal glycinergic responses. These data suggest that most glycine receptors in the mouse laminae I/II contain $\alpha 1$ subunits. Thus, using antibody to GLR $\alpha 1$ to assess synapses with glycine receptors reflects the majority of glycinergic synapses.

High-resolution confocal imaging was used to identify individual puncta with each immunolabel (Fig. 8A-G). Colocalization of VGAT + and gephyrin + puncta was used to estimate the total number of inhibitory synapses in the lamina IIi-III border region (Fig. 8E-G; see Materials and Methods). Overlap of VGAT + and gephyrin + , together with GLR $\alpha 1$ puncta, enabled us to estimate the number of synapses that included a GLR $\alpha 1$ glycinergic component. Figure $8 D$ shows an example of a triplelabeled spinal cord dorsal horn at low resolution. Figure $8 E-G$ shows the puncta observed at higher resolution.

Analysis of these immunohistochemical data are shown in Figure $8 H, I$. There was no change in the density of inhibitory synapses near the lamina IIi-III border $(100-150 \mu \mathrm{m})$ or in lam- 
A



B

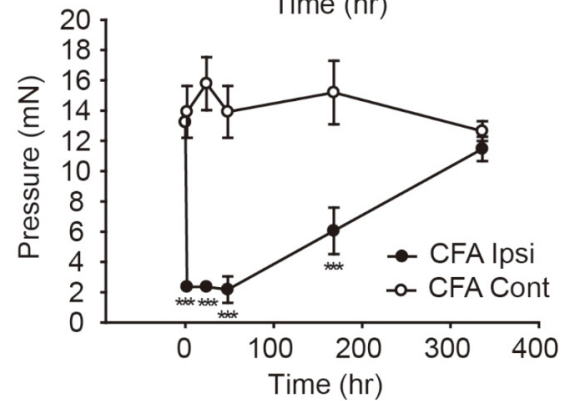

C

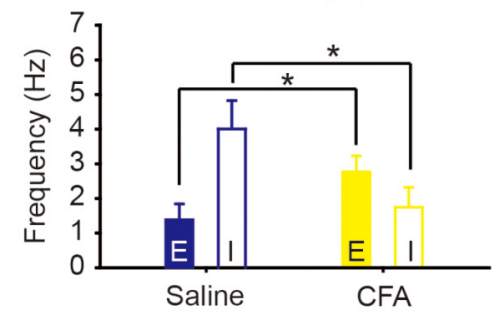

D
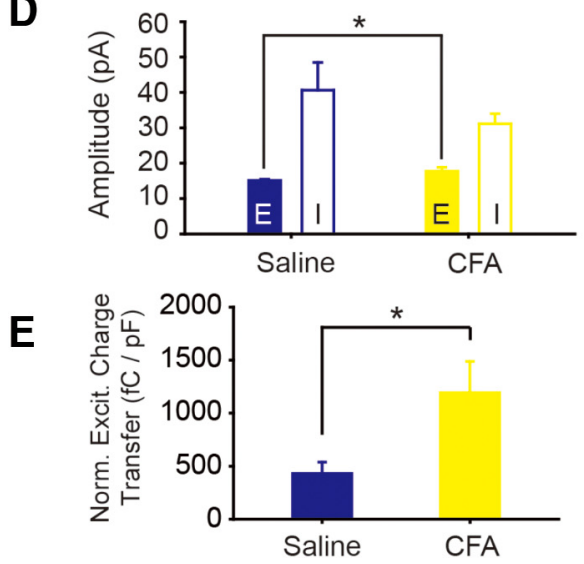

Figure 6. The balance between synaptic excitatory and inhibitory inputs on excitatory neurons located in laminae Ili and III in the spinal cord was changed after peripheral inflammation. $A, B$, CFA injection to hindpaw of mice significantly decreased the nociceptive escape threshold for thermal $(\boldsymbol{A})$ and mechanical $(\boldsymbol{B})$ stimuli (Tukey's post hoc test). Hargreave's and von Frey tests were performed before and $2 \mathrm{~h}, 24 \mathrm{~h}, 48 \mathrm{~h}, 7 \mathrm{~d}$, and $14 \mathrm{~d}$ after the injection. C, The frequency of $\mathrm{sEPSC}$ s was greater in CFA-injected mice (filled yellow bar, $n=21$ ) than in salineinjected mice (filled blue bar, $n=17$ ). The frequency of $s$ IPSC was smaller in (FA-injected mice (open yellow bar, $n=21$ ) than in saline-injected mice (open blue bar, $n=17$ ). $\boldsymbol{D}$, The amplitude of sEPSCs was greater in (FA-injected mice (filled yellow bar, $n=21$ ) than in salineinjected mice (filled blue bar, $n=17$ ). $\boldsymbol{E}$, After being normalized by cell capacitance, total excitatory charge transfer was greater in (FA-injected mice (filled yellow bar, $n=21$ ) than in saline-injected mice (filled blue bar, $n=17$ ). Data are shown as means \pm SEM. ${ }^{*} p<0.05$, ${ }^{* * *} p<0.001$.

inae III/IV (150-200 $\mu \mathrm{m})$ with saline or CFA injection as seen in Figure $8 \mathrm{H}$. Similarly, there was no change in the percentage of inhibitory synapses with detectable levels of GLR $\alpha 1$ (Fig. 8I). The absence of immunohistochemical support for detectable changes in inhibitory synapses in the lamina IIi-III border region while
A

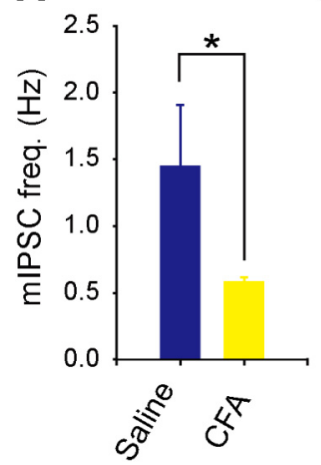

B
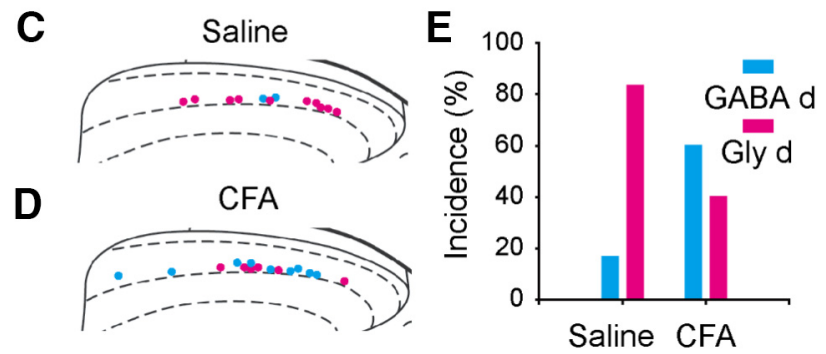

Figure 7. Synaptic inhibition of excitatory neurons located in lamina lli changed after peripheral inflammation. $A$, The frequency of mIPSCs recorded from excitatory neurons located in lamina Ili from CFA-injected mice was lower than that in saline-injected mice ( $n=15$ and 12, respectively; $p<0.05$, unpaired $t$ test). $\boldsymbol{B}$, Excitatory neurons located in lamina lli could be divided into two distinct populations, Gly-d or GABA-d, on the basis of the property of inhibitory synaptic inputs. Blue and yellow triangles indicate individual neurons recorded from salineinjected and CFA-injected mice, respectively. C, D, Soma locations of Gly-d (pink circles) and GABA-d (blue circles) neurons in saline-injected and CFA-injected mice ( $n=12$ and 15 , respectively). $\boldsymbol{E}$, The percentage of Gly-d and GABA-d neurons changed after CFA injection ( $p<0.05$, Fisher's exact test).

there was a sharp shift from Gly-d to GABA-d inhibition of excitatory interneurons suggests the possibility that modification of receptor properties is the most likely explanation for the dominance shift.

\section{Discussion}

Selective recordings from putative excitatory neurons

The heterogeneous populations of excitatory and inhibitory interneurons in the spinal cord dorsal horn have important roles in normal sensory processing and in the generation of pathological pain. In an early effort to understand their differential contributions to dorsal horn circuitry, a scheme to functionally distinguish excitatory and inhibitory neurons within lamina II classified them mainly by their somatodendritic morphology (Grudt and Perl, 2002) and functional connectivity (Lu and Perl, 2005; Zheng et al., 2010). More recently, considerable progress has been made using genetic markers to identify subpopulations of neurons contributing to specific circuitries within this small region of the CNS (Duan et al., 2014; Peirs et al., 2015). We have used GIN mice and recorded from EGFP ${ }^{-}$neurons to study the broader population of putative excitatory neurons within the dorsal horn, enabling us to search for regional differences in inhibitory control.

One issue of concern is how representative the $\mathrm{EGFP}^{-}$neurons are of the entire excitatory neuron population in laminae I-III. We demonstrate here that we improved the odds of recording from excitatory neurons to $\sim 90 \%$ using EGFP $^{-}$neurons. This calculation assumed that glycinergic neurons coexpress GABA, and therefore GAD, in mouse dorsal horn (Polgár et al., 



F GLRA1

G VGAT/gephyrin/GLRA1
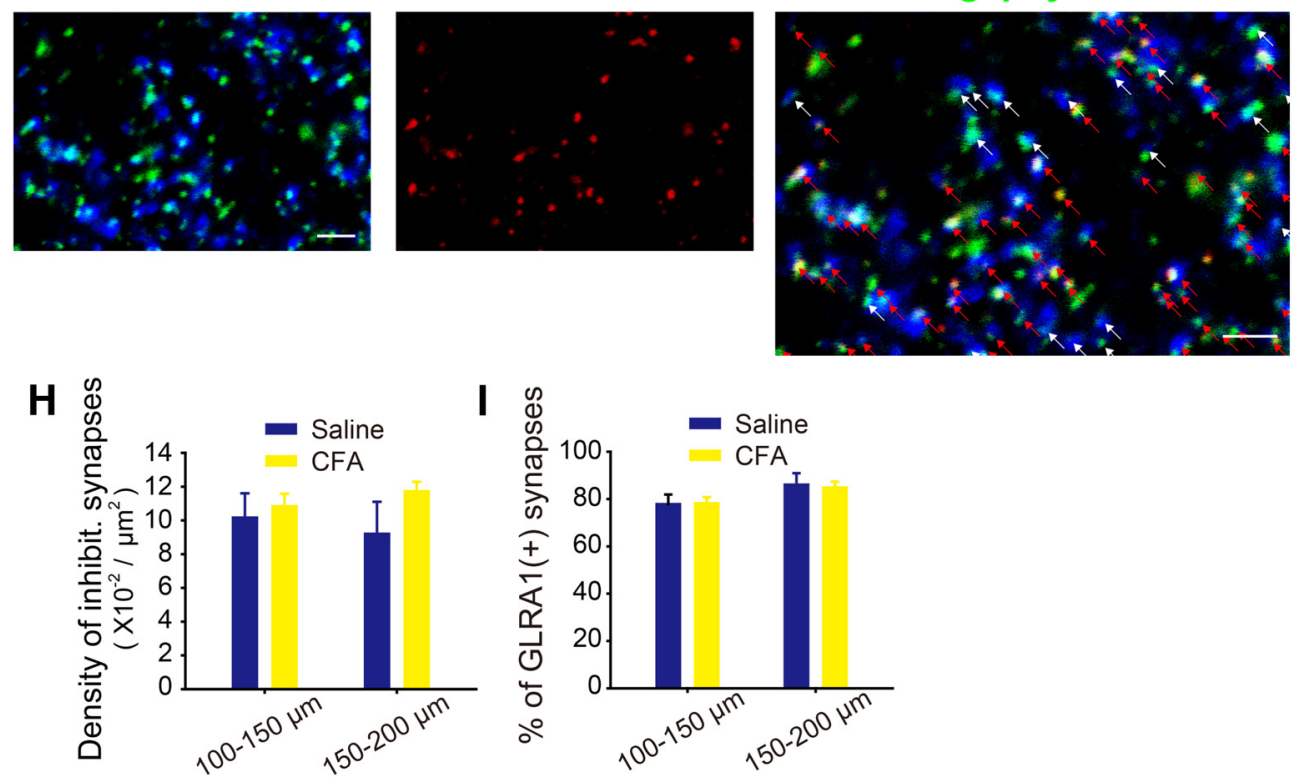

Figure 8. Spinal cord dorsal horns from GIN P26 mice (saline and (FA injected) were stained with antibodies to show inhibitory synapses with and without GLR $\alpha 1$. $A-C$, Anti-VGAT (A, blue), anti-gephyrin ( $\boldsymbol{B}$, green), and anti-GLR $\alpha 1$ ( $\boldsymbol{C}$, red) were used. Unstained EGFP is also apparent as green fluorescence in $\boldsymbol{B}$. $\boldsymbol{D}$, Merged images with the three antibodies. Scale bar, $100 \mu \mathrm{m}$. $\boldsymbol{E}$ - $\boldsymbol{G}$, Images at high resolution for counting synapses. Colocalization of VGAT + and gephyrin puncta, evidence of inhibitory synapses, were marked with arrows in $G$. Inhibitory synapses with and without GLR $\alpha 1$ immunoreactivity were indicated by red and white arrows, respectively. Scale bar, $2 \mu \mathrm{m}$. $\boldsymbol{H}$, Average density of inhibitory synapses (colocalization of VGAT+ and gephyrin puncta) within the regions counted. $I$, Average percentage of inhibitory synapses that are $G L R \alpha 1(+)$ from both lamina levels counted are plotted for both saline-injected $(n=3)$ and CFA-injected $(n=3)$ mice.

2013). An alternative approach to ours was to directly identify excitatory neurons using EGFP driven by the vGluT2 promoter. However, study of vGluT2::EGFP bacterial artificial chromosome (BAC) transgenic mice revealed only about one-third of all excitatory dorsal horn neurons express EGFP under these conditions (Punnakkal et al., 2014). With our approach, despite inclusion of some glycinergic neurons, our $\mathrm{EGFP}^{-}$neurons were a highly enriched excitatory population of dorsal horn neurons.

\section{Mixed glycine and $\mathrm{GABA}_{\mathrm{A}}$ receptors mediated mIPSCs}

Estimates of the dominance of glycine and GABA as fast inhibitory transmitters in the dorsal horn have traditionally depended upon analysis of recorded mIPSCs. In our analysis, mIPSC decay taus and sensitivity of mIPSC amplitudes to bicuculline were used to define dominance. We found putative excitatory neurons to be GABA-d in laminae I/IIo and to be Gly-d in laminae IIi and III. A few neurons showed purely glycinergic or GABAergic mIPSCs and these localized with Gly-d and GABA-d neurons respectively, which is similar to findings from our previous studies with inhibitory neurons in GIN mice (Takazawa and MacDermott, 2010b). In another study, more than half of neurons that were EGFP ${ }^{+}$excitatory neurons in the vGluT2::EGFP BAC P17P28 mice received mixed $\mathrm{GABA}_{\mathrm{A}}$ receptor-mediated and glycine receptor-mediated polysynaptic inputs driven by primary affer- ent stimulation. However, $>25 \%$ of the remaining neurons received exclusively glycinergic input (Punnakkal et al., 2014). While these recordings were made in laminae I and II, we would predict they were mainly in the lamina II-III border area as that is where Gly-d neurons are prominent in our experiments.

\section{GABA-d and Gly-d synaptic input consistent with density of} GABAergic and glycinergic neurons

Excitatory neurons in the dorsal horn are known to be heterogeneous in their neurochemistry, afferent inputs, and firing properties and thus are likely to be heterogeneous in how their excitability is regulated (Yasaka et al., 2010; Punnakkal et al., 2014). Glycine and $\mathrm{GABA}_{\mathrm{A}}$ receptors are both present on many postsynaptic membranes in spinal cord dorsal horn, although some synapses have exclusively either glycine or $\mathrm{GABA}_{\mathrm{A}}$ receptors (Todd et al., 1996). Immunohistochemical studies show that expression of GLR $\alpha 1$ subunits gradually increases from dorsal to ventral in the dorsal horn (Harvey et al., 2004), while $\mathrm{GABA}_{\mathrm{A}}$ receptor $\beta 3$ subunits are most dense in laminae I and II (Todd et al., 1996), although the distribution pattern of $\mathrm{GABA}_{\mathrm{A}}$ receptors varies with the different $\mathrm{GABA}_{\mathrm{A}}$ receptor subunits (Bohlhalter et al., 1996).

Inhibitory neurons synapse mostly on other neurons within the same laminar location in the spinal cord dorsal horn (Kato et 
al., 2009). We show that glycinergic neurons are located prominently in the lamina II-III border. This distribution of glycine immunoreactivity is similar to that reported in rats (Todd and Sullivan, 1990) and mice (Polgár et al., 2013; Punnakkal et al., 2014). The Gly-d we demonstrate here in the lamina II-III border codistributes with the glycinergic neurons there. GABAergic neurons are more prominent in lamina I, lamina IIo, and the dorsal portion of lamina IIi and this is consistent with the general GABA-d of synaptic input demonstrated here.

\section{Postsynaptic receptor modification resulting in a shift from Gly-d to GABA-d}

Following peripheral inflammation, we show a shift from Gly-d of inhibition of putative excitatory neurons in the lamina II-III border area to GABA-d. This was accompanied by enhanced excitatory charge transfer and an overall decrease in mIPSC frequency. These prominent changes in inhibition raise the question of whether they reflect a loss of glycinergic inhibitory input, an enhancement of GABA input, a shift in transmitter receptor expression, or inflammation-associated modulation of GABA or glycine receptor function.

During peripheral inflammation, many chemical mediators, including cytokines and prostanoids, are released into the spinal cord. One of the inflammatory mediators, prostaglandin $\mathrm{E}_{2}\left(\mathrm{PGE}_{2}\right)$, selectively inhibits glycinergic neurotransmission (Ahmadi et al., 2002). Glycine receptor $\alpha 3$ (GLR $\alpha 3$ ) subunit is known as a target for such $\mathrm{PGE}_{2}$-induced modulation of glycinergic transmission (Ahmadi et al., 2002). GLR $\alpha 3$ is predominantly expressed in lamina II and overlaps with GLR $\alpha 1$, the latter of which becomes the predominant subunit expressed ventral from lamina II (Harvey et al., 2004). At the lamina II-III border, many synapses express both glycine receptor subunits (Harvey et al., 2004). Besides, proinflammatory cytokines, including IL-1 $\beta$ and IL-6, reportedly reduced glycinergic inhibition on dorsal horn neurons (Kawasaki et al., 2008). Therefore, the shift to GABA-d in that region may be, in part, due to inhibition of glycine receptors.

Synaptic inhibition mediated by $\mathrm{GABA}_{\mathrm{A}}$ receptors in lamina II is markedly increased by activation of endogenous neurosteroidbased antinociceptive control during peripheral inflammation (Poisbeau et al., 2005). Decay time constants of GABAergic mIPSCs recorded from inflamed animals were significantly longer than those of saline-injected controls. Also, a reduction occurs in the proportion of glycinergic mIPSCs replaced by mixed GABAergic/glycinergic mIPSCs (Poisbeau et al., 2005). These observations may help explain the inflammationinduced changes in mIPSCs we report here because enhancement and prolongation of the GABAergic component of mIPSCs is expected to contribute to the shift to GABA-d at the lamina II-III border with inflammation.

Using our morphological analysis, we were unable to detect any changes in inhibitory synapses caused by CFA-induced inflammation. This is consistent with the idea that synaptic inhibition was modulated after peripheral inflammation through a change in functioning of existing glycine and $\mathrm{GABA}_{\mathrm{A}}$ receptors but not morphological changes.

\section{How could this impact behavior?}

Spontaneous excitatory inputs onto putative excitatory neurons located at the lamina II-III border was greater in CFA-injected mice than that in saline-injected mice while inhibition was less. The excitatory PKC $\gamma$ neurons at the lamina II-III border area receive inputs from myelinated low-threshold afferents association with touch (Neumann et al., 2008). These could be the be- ginning of a circuitry associated with mechanical allodynia in that they receive touch input but can drive excitation up toward lamina I nociceptive output neurons. Increased excitability of $\mathrm{PKC} \gamma^{+}$neurons in the lamina II-III border was shown to induce excitability in transient central neurons at lamina IIo (Lu et al., 2013). Thus, excitatory synaptic drive was observed to flow from the lamina II-III border dorsally across lamina II toward lamina I via neurons with long ventral dendrites called vertical neurons. These transient central and vertical neurons receive highthreshold $\mathrm{A} \delta$-fiber and C-fiber inputs and normally respond to noxious mechanical and thermal stimuli ( $\mathrm{Lu}$ and Perl, 2005; Maxwell et al., 2007; Kato et al., 2009; Takazawa and MacDermott, 2010a; Todd, 2010). Thus, depression of mIPSC frequency in the lamina II-III border where PKC $\gamma$ neurons are located accompanies the shift of inhibition from Gly-d to GABA-d and may contribute to mechanical allodynia associated with peripheral inflammation.

Although we did not test whether excitability of neurons in lamina IIo changed after CFA-induced inflammation, the enhanced excitation of neurons in lamina II-III border due to local disinhibition could drive lamina IIo neurons to fire action potentials. TRPV1 ${ }^{+}$afferent fibers, which terminate in laminae I and IIo, are responsible for heat and mechanical pain sensitivity (Cavanaugh et al., 2009; Duan et al., 2014). This suggests that increased excitation of neurons in lamina IIo could result in a hypersensitivity to both heat and mechanical pain. Therefore, hyperexcitability of neurons at the lamina II-III border due to paw inflammation could be sufficient to induce both thermal hyperalgesia and mechanical allodynia as shown in our behavioral tests. However, further studies to clarify changes in inhibitory inputs onto dorsal horn neurons other than lamina II-III border neurons are necessary to fully understand the mechanisms underlying abnormal nociception after peripheral inflammation.

\section{References}

Ahmadi S, Lippross S, Neuhuber WL, Zeilhofer HU (2002) PGE(2) selectively blocks inhibitory glycinergic neurotransmission onto rat superficial dorsal horn neurons. Nat Neurosci 5:34-40. CrossRef Medline

Baccei ML, Fitzgerald M (2004) Development of GABAergic and glycinergic transmission in the neonatal rat dorsal horn. J Neurosci 24:4749-4757. CrossRef Medline

Bohlhalter S, Weinmann O, Mohler H, Fritschy JM (1996) Laminar compartmentalization of $\mathrm{GABA}_{\mathrm{A}}$-receptor subtypes in the spinal cord: an immunohistochemical study. J Neurosci 16:283-297. Medline

Cameron D, PolgárE, Gutierrez-Mecinas M, Gomez-Lima M, Watanabe M, Todd AJ (2015) The organisation of spinoparabrachial neurons in the mouse. Pain 156:2061-2071. CrossRef Medline

Cavanaugh DJ, Lee H, Lo L, Shields SD, Zylka MJ, Basbaum AI, Anderson DJ (2009) Distinct subsets of unmyelinated primary sensory fibers mediate behavioral responses to noxious thermal and mechanical stimuli. Proc Natl Acad Sci U S A 106:9075-9080. CrossRef Medline

Chéry N, de Koninck Y (1999) Junctional versus extrajunctional glycine and GABA(A) receptor-mediated IPSCs in identified lamina I neurons of the adult rat spinal cord. J Neurosci 19:7342-7355. Medline

Dougherty KJ, Sawchuk MA, Hochman S (2005) Properties of mouse spinal lamina I GABAergic interneurons. J Neurophysiol 94:3221-3227. CrossRef Medline

Dougherty KJ, Sawchuk MA, Hochman S (2009) Phenotypic diversity and expression of GABAergic inhibitory interneurons during postnatal development in lumbar spinal cord of glutamic acid decarboxylase 67-green fluorescent protein mice. Neuroscience 163:909-919. CrossRef Medline

Duan B, Cheng L, Bourane S, Britz O, Padilla C, Garcia-CampmanyL, Krashes M, Knowlton W, Velasquez T, Ren X, Ross SE, Lowell BB, Wang Y, Goulding M, Ma Q (2014) Identification of spinal circuits transmitting and gating mechanical pain. Cell 159:1417-1432. CrossRef Medline Graham BA, Tadros MA, Schofield PR, Callister RJ (2011) Probing glycine 
receptor stoichiometry in superficial dorsal horn neurones using the spasmodic mouse. J Physiol 589:2459-2474. CrossRef Medline

Grudt TJ, Perl ER (2002) Correlations between neuronal morphology and electrophysiological features in the rodent superficial dorsal horn. J Physiol 540:189-207. CrossRef Medline

Harvey RJ, Depner UB, Wässle H, Ahmadi S, Heindl C, Reinold H, Smart TG, Harvey K, Schütz B, Abo-Salem OM, Zimmer A, Poisbeau P, Welzl H, Wolfer DP, Betz H, Zeilhofer HU, Müller U (2004) GlyR alpha3: an essential target for spinal PGE2-mediated inflammatory pain sensitization. Science 304:884-887. CrossRef Medline

Heinke B, Ruscheweyh R, Forsthuber L, Wunderbaldinger G, Sandkühler J (2004) Physiological, neurochemical and morphological properties of a subgroup of GABAergic spinal lamina II neurones identified by expression of green fluorescent protein in mice. J Physiol 560:249-266. CrossRef Medline

Jonas P, Bischofberger J, Sandkühler J (1998) Corelease of two fast neurotransmitters at a central synapse. Science 281:419-424. CrossRef Medline

Kato G, Kawasaki Y, Koga K, Uta D, Kosugi M, Yasaka T, Yoshimura M, Ji RR, Strassman AM (2009) Organization of intralaminar and translaminar neuronal connectivity in the superficial spinal dorsal horn. J Neurosci 29:5088-5099. CrossRef Medline

Kawasaki Y, Zhang L, Cheng JK, Ji RR (2008) Cytokine mechanisms of central sensitization: distinct and overlapping role of interleukin- $1 \beta$, interleukin-6, and tumor necrosis factor- $\alpha$ in regulating synaptic and neuronal activity in the superficial spinal cord. J Neurosci 28:5189-5194. CrossRef Medline

Keller AF, Coull JA, Chery N, Poisbeau P, De Koninck Y (2001) Regionspecific developmental specialization of GABA-glycine cosynapses in laminas I-II of the rat spinal dorsal horn. J Neurosci 21:7871-7880. Medline

Labrakakis C, MacDermott AB (2003) Neurokinin receptor 1-expressing spinal cord neurons in lamina I and III/IV of postnatal rats receive inputs from capsaicin sensitive fibers. Neurosci Lett 352:121-124. CrossRef Medline

Lu Y, Perl ER (2005) Modular organization of excitatory circuits between neurons of the spinal superficial dorsal horn (laminae I and II). J Neurosci 25:3900-3907. CrossRef Medline

Lu Y, Dong H, Gao Y, Gong Y, Ren Y, Gu N, Zhou S, Xia N, Sun YY, Ji RR, Xiong L (2013) A feed-forward spinal cord glycinergic neural circuit gates mechanical allodynia. J Clin Invest 123:4050-4062. CrossRef Medline

Lynch JW, Callister RJ (2006) Glycine receptors: a new therapeutic target in pain pathways. Curr Opin Investig Drugs 7:48-53. Medline

Maxwell DJ, Belle MD, Cheunsuang O, Stewart A, Morris R (2007) Morphology of inhibitory and excitatory interneurons in superficial laminae of the rat dorsal horn. J Physiol 584:521-533. CrossRef Medline

Miraucourt LS, Dallel R, Voisin DL (2007) Glycine inhibitory dysfunction turns touch into pain through PKCgamma interneurons. PLoS ONE 2:e1116. CrossRef Medline

Mitchell EA, Gentet LJ, Dempster J, Belelli D (2007) GABAA and glycine receptor-mediated transmission in rat lamina II neurones: relevance to the analgesic actions of neuroactive steroids. J Physiol 583:1021-1040. CrossRef Medline

Müller F, Heinke B, Sandkühler J (2003) Reduction of glycine receptormediated miniature inhibitory postsynaptic currents in rat spinal lamina I neurons after peripheral inflammation. Neuroscience 122:799-805. CrossRef Medline

Neumann S, Braz JM, Skinner K, Llewellyn-Smith IJ, Basbaum AI (2008) Innocuous, not noxious, input activates PKCgamma interneurons of the spinal dorsal horn via myelinated afferent fibers. J Neurosci 28:79367944. CrossRef Medline

Oliva AA Jr, Jiang M, Lam T, Smith KL, Swann JW (2000) Novel hippocampal interneuronal subtypes identified using transgenic mice that express green fluorescent protein in GABAergic interneurons. J Neurosci 20: 3354-3368. Medline

Peirs C, Patil S, Bouali-Benazzouz R, Artola A, Landry M, Dallel R (2014) Protein kinase $\mathrm{C}$ gamma interneurons in the rat medullary dorsal horn: Distribution and synaptic inputs to these neurons, and subcellular localization of the enzyme. J Comp Neurol 522:393-413. CrossRef Medline

Peirs C, Williams SP, Zhao X, Walsh CE, Gedeon JY, Cagle NE, Goldring AC,
Hioki H, Liu Z, Marell PS, Seal RP (2015) Dorsal horn circuits for persistent mechanical pain. Neuron 87:797-812. CrossRef Medline

Poisbeau P, Patte-Mensah C, Keller AF, Barrot M, Breton JD, Luis-Delgado OE, Freund-Mercier MJ, Mensah-Nyagan AG, Schlichter R (2005) Inflammatory pain upregulates spinal inhibition via endogenous neurosteroid production. J Neurosci 25:11768-11776. CrossRef Medline

Polgár E, Durrieux C, Hughes DI, Todd AJ (2013) A quantitative study of inhibitory interneurons in laminae I-III of the mouse spinal dorsal horn. PLoS One 8:e78309. CrossRef Medline

Punnakkal P, von Schoultz C, Haenraets K, Wildner H, Zeilhofer HU (2014) Morphological, biophysical and synaptic properties of glutamatergic neurons of the mouse spinal dorsal horn. J Physiol 592:759-776. CrossRef Medline

Rajalu M, Müller UC, Caley A, Harvey RJ, Poisbeau P (2009) Plasticity of synaptic inhibition in mouse spinal cord lamina II neurons during early postnatal development and after inactivation of the glycine receptor alpha3 subunit gene. Eur J Neurosci 30:2284-2292. CrossRef Medline

Ross SE (2011) Pain and itch: insights into the neural circuits of aversive somatosensation in health and disease. Curr Opin Neurobiol 21:880887. CrossRef Medline

Ross SE, Mardinly AR, McCord AE, Zurawski J, Cohen S, Jung C, Hu L, Mok SI, Shah A, Savner EM, Tolias C, Corfas R, Chen S, Inquimbert P, Xu Y, McInnes RR, Rice FL, Corfas G, Ma Q, Woolf CJ, et al. (2010) Loss of inhibitory interneurons in the dorsal spinal cord and elevated itch in Bhlhb5 mutant mice. Neuron 65:886-898. CrossRef Medline

Takazawa T, MacDermott AB (2010a) Synaptic pathways and inhibitory gates in the spinal cord dorsal horn. Ann N Y Acad Sci 1198:153-158. CrossRef Medline

Takazawa T, MacDermott AB (2010b) Glycinergic and GABAergic tonic inhibition fine tune inhibitory control in regionally distinct subpopulations of dorsal horn neurons. J Physiol 588:2571-2587. CrossRef Medline

Tibbs GR, Rowley TJ, Sanford RL, Herold KF, Proekt A, Hemmings HC Jr, Andersen OS, Goldstein PA, Flood PD (2013) HCN1 channels as targets for anesthetic and nonanesthetic propofol analogs in the amelioration of mechanical and thermal hyperalgesia in a mouse model of neuropathic pain. J Pharmacol Exp Ther 345:363-373. CrossRef

Todd AJ (2010) Neuronal circuitry for pain processing in the dorsal horn. Nat Rev Neurosci 11:823-836. CrossRef Medline

Todd AJ, Spike RC (1993) The localization of classical transmitters and neuropeptides within neurons in laminae I-III of the mammalian spinal dorsal horn. Prog Neurobiol 41:609-645. CrossRef Medline

Todd AJ, Sullivan AC (1990) Light microscope study of the coexistence of GABA-like and glycine-like immunoreactivities in the spinal cord of the rat. J Comp Neurol 296:496-505. CrossRef Medline

Todd AJ, Watt C, Spike RC, Sieghart W (1996) Colocalization of GABA, glycine, and their receptors at synapses in the rat spinal cord. J Neurosci 16:974-982. Medline

Tong CK, MacDermott AB (2014) Synaptic GluN2A and GluN2B containing NMDA receptors within the superficial dorsal horn activated following primary afferent stimulation. J Neurosci 34:10808-10820. CrossRef Medline

Torsney C, MacDermott AB (2006) Disinhibition opens the gate to pathological pain signaling in superficial neurokinin 1 receptor-expressing neurons in rat spinal cord. J Neurosci 26:1833-1843. CrossRef Medline

Udesky JO, Spence NZ, Achiel R, Lee C, Flood P (2005) The role of nicotinic inhibition in ketamine-induced behavior. Anesth Analg 101:407-411, table of contents. CrossRef Medline

Wang X, Zhang J, Eberhart D, Urban R, Meda K, Solorzano C, Yamanaka H, Rice D, Basbaum AI (2013) Excitatory superficial dorsal horn interneurons are functionally heterogeneous and required for the full behavioral expression of pain and itch. Neuron 78:312-324. CrossRef Medline

Yasaka T, Tiong SY, Hughes DI, Riddell JS, Todd AJ (2010) Populations of inhibitory and excitatory interneurons in lamina II of the adult rat spinal dorsal horn revealed by a combined electrophysiological and anatomical approach. Pain 151:475-488. CrossRef Medline

Zeilhofer HU, Benke D, Yevenes GE (2012) Chronic pain states: pharmacological strategies to restore diminished inhibitory spinal pain control. Annu Rev Pharmacol Toxicol 52:111-133. CrossRef Medline

Zheng J, Lu Y, Perl ER (2010) Inhibitory neurones of the spinal substantia gelatinosa mediate interaction of signals from primary afferents. J Physiol 588:2065-2075. CrossRef Medline 